\title{
Adsorption of Azo-Anionic Dyes in a Solution Using Modified Coconut (Cocos nucifera) Mesocarp: Kinetic and Equilibrium Study
}

\author{
Candelaria Tejada-Tovar ${ }^{1}\left[\right.$, Ángel Villabona-Ortíz ${ }^{1}\left(\mathbb{D}\right.$ and Ángel Darío Gonzalez-Delgado ${ }^{2, *}$ (i) \\ 1 Process Design and Biomass Utilization Research Group (IDAB), Chemical Engineering Department, \\ University of Cartagena, Avenida del Consulado St. 30, Cartagena de Indias 130015, Colombia; \\ ctejadat@unicartagena.edu.co (C.T.-T.); avillabonao@unicartagena.edu.co (Á.V.-O.) \\ 2 Nanomaterials and Computer Aided Process Engineering Research Group (NIPAC), Chemical Engineering \\ Department, University of Cartagena, Avenida del Consulado St. 30, Cartagena de Indias 130015, Colombia \\ * Correspondence: agonzalezd1@unicartagena.edu.co
}

check for updates

Citation: Tejada-Tovar, C.;

Villabona-Ortíz, Á.;

Gonzalez-Delgado, Á.D. Adsorption of Azo-Anionic Dyes in a Solution Using Modified Coconut (Cocos nucifera) Mesocarp: Kinetic and Equilibrium Study. Water 2021, 13, 1382. https://doi.org/10.3390/ w13101382

Academic Editor: Cidália Botelho

Received: 5 April 2021

Accepted: 13 May 2021

Published: 15 May 2021

Publisher's Note: MDPI stays neutral with regard to jurisdictional claims in published maps and institutional affiliations.

Copyright: (c) 2021 by the authors. Licensee MDPI, Basel, Switzerland. This article is an open access article distributed under the terms and conditions of the Creative Commons Attribution (CC BY) license (https:/ / creativecommons.org/licenses/by/ $4.0 /)$.

\begin{abstract}
The effect of adsorbent dose and initial concentration on removing the azo-anionic dyes Congo Red andtartrazine present in a synthetic aqueous solution was studied using natural cellulose (CC) and modified cationic cellulose (MCC) from coconut mesocarp. Three levels of adsorbent dosage (5, 8 and $12 \mathrm{mg} / \mathrm{L}$ ) and initial concentration (40, 70 and $100 \mathrm{mg} / \mathrm{L}$ ) were used. Cetyl trimethyl ammonium chloride (CTAC) was used as a modifying agent. TGA and DSC showed that the extracted cellulose was of good quality, composed mostly of cellulose with lignin and hemicellulose traces, and $8 \%$ moisture. The FTIR spectrum showed the effectiveness of the modification in the structure of the material with symmetric deformation of the $\mathrm{C}_{6} \mathrm{H}_{6}-\mathrm{Cl}$ group in $1472 \mathrm{~cm}^{-1}$ present in the CTAC. It was found that decreasing the adsorbent dosage and increasing the initial concentration favored the dyes' adsorption capacity on the two bioadsorbents. Tartrazine removals of $5.67 \mathrm{mg} / \mathrm{g}$ on CC and $19.61 \mathrm{mg} / \mathrm{g}$ on MCC were achieved, and for CR of $15.52 \mathrm{mg} / \mathrm{g}$ on CC and 19.99 with MCC with removal percentages over $97 \%$ with the quaternized biomass in all cases. The kinetic and equilibrium study was carried out to identify the mechanisms involved in the adsorption process. The Freundlich model can describe the equilibrium isotherm data of tartrazine on CC and MCC. In contrast, those of CR is defined by the Langmuir and Dubinin-Radushkevic models for CC and MCC, respectively Adsorption kinetics showed that equilibrium was reached at $30 \mathrm{~min}$, with rapid adsorption in the initial minutes with the removal of about $97 \%$ of the contaminant in the first 5 min; fitting to kinetic models showed that the kinetics of tartrazine on CC was fitted by Elovich $\left(R^{2}=0.756\right)$, and on MCC the Elovich $\left(\mathrm{R}^{2}=0.887\right)$ and pseudo-second-order $\left(\mathrm{R}^{2}=0.999\right)$ models. Removing CR on CC was fitted by pseudo-first-order, pseudo-second-order and Elovich models $\left(\mathrm{R}^{2}>0.98\right)$, and when using MCC, all models show a good fitting with $\mathrm{R}^{2}=0.99$ in all cases.
\end{abstract}

Keywords: adsorption; cellulose; quaternization; tartrazine; Congo red

\section{Introduction}

Dyes are ionic aromatic organic compounds with structures that include aryl groups that have delocalized electron systems, and when bound to a material gives color to the material [1]. About 7000 different chemical structures have been identified that absorb or emit light in the visible spectrum range [2]. It has been estimated that there are more than 100,000 dyes and colorants commercially available and more than $7 \times 10^{5}$ tons are produced annually worldwide [3]. Their presence in effluents is cause for great concern because they change the spectrophotometry of wastewater from industries such as food and textiles. Their metabolites and by-products obtained, once they come into contact with surface effluents such as lakes and rivers, can cause carcinoma, and damage to the nervous system and urinary system of living beings [4]. Nowadays, the textile industry uses around 
3600 dyes and 8000 different chemicals products in various processes, including bleaching, dyeing, printing and finishing [5].

The great demand for colorants due to their application in different industrial sectors generates a large volume of colored residual effluents and post-production waste. Among these, the textile industry discharges high volumes of wastewater into aquatic environments, since during the dyeing processes between $5 \%$ and $50 \%$ is wasted, depending on the type of fabric and dye, resulting in almost 200 billion liters of effluents with dyes per year [6]. For their part, the dyeing industries use large volumes of water and dyes, pouring $8 \%$ to $20 \%$ of colorants and additives into the wastewater streams from the textile industries [7]. Thus, tons of dyes are dumped into the environment as waste daily [8]. Many of the synthetic organic dyes are not biodegradable or do so slowly, which makes it difficult to eliminate them using conventional methods available in wastewater treatment plants [9]. The discharge of effluents contaminated with dyes without treatment affects the health of water bodies because it reduces the photosynthetic capacity of sub-aquatic plants, increases COD and causes eutrophication of surface waters [10]. Likewise, the toxic properties of some dyes have been confirmed, including carcinogenic [11], mutagenic [12], allergic and dermatological [13] effects. Even at trace levels $(<1 \mathrm{mg} / \mathrm{L})$, these compounds have adverse health effects [9]. This confirms that synthetic organic colorants pose an environmental problem for aquatic ecosystems, and for this reason, it is necessary to treat wastewater containing dyes before it is discharged into the environment.

Various chemical and physical processes such as flocculation, chemical coagulation, precipitation, and adsorption have been widely used to treat dye-bearing wastewater, with adsorption being one of the most efficient methods [14]. Agricultural wastes are an excellent source for dye adsorption. They are cheap and abundantly available, mainly consisting of cellulose, hemicellulose and lignin that bind as effective adsorbents for a wide range of contaminants containing the functional groups hydroxyl, carboxyl, phenols, methoxy, etc. [15]. The development of green adsorbents such as cellulose for dye adsorption is receiving widespread attention due to their non-toxicity, renewal capacity and high economic value [16].

The use of cellulose as a bioadsorbent is recent, as it was used in reducing sugars or raw material to produce ethanol or for the paper industry [17]. Cellulose can be modified to improve its dye and colorant retention action. The most commonly used modification method is quaternization, which is an etherification reaction in which a quaternary ammonium salt reacts with cellulose to derive a positively charged product (cationic cellulose) $[18,19]$. A quaternary ammonium salt is useful as an etherifying agent for cellulose; one of the most used for the synthesis of quaternized cellulose is cetyl trimethyl ammonium chloride. This compound is $70 \%$ degradable to stable compounds, in its configuration the nitrogen takes valence IV; thus, the cellulose reacts with the cetyl trimethylammonium chloride creating a cationic surface, displacing the hydrogens present in the $\mathrm{OH}$ group or otherwise the whole group [20].

The adsorption equilibrium has been studied using isotherms, in order to identify how the analyte molecules in question are distributed between the liquid phase and the solid phase when the adsorption process reaches an equilibrium state [21]. The data used to obtain isotherms can be fitted by different models to study the nature of the process and can be used to compare the efficiency [22,23]. The adsorption equilibrium of Congo Red and Methylene Blue (MB) on activated carbons from ashitaba residues and walnut shells modified with Zinc Chloride has been investigated, finding that the bioadsorbents from ashitaba residues showed selectivity for $\mathrm{CR}$ reaching a maximum adsorption capacity of $632.13 \mathrm{mg} / \mathrm{g}$, indicating their selectivity for the material; a maximum MB adsorption capacity of $400.11 \mathrm{mg} / \mathrm{g}$ was achieved on walnut shell biochar [24]. The study of tartrazine removal on activated carbon from moringa seeds showed a better fit of the experimental data of the isotherm to the Freundlich model because it was assumed that the removal process of the contaminant occurred in multilayers inside the pores of the bioadsorbent, achieving a maximum removal capacity of $44.02 \mathrm{mg} / \mathrm{g}$ [25]. 
Additionally, different methodologies have been proposed for the reuse of bioadsorbent materials, in order to extend their useful life, as well as to recover the dye in a concentrated solution after each desorption cycle, using $\mathrm{NaOH}, \mathrm{HCl}$, acetic acid and organic solvent mixtures [26]. This successfully demonstrates the possibility of regenerating and reusing adsorbent materials, as well as obtaining removal efficiencies $>60 \%$ after six adsorption cycles [27]. Regarding the final disposal of the adsorbents once they are aged after the desorption cycles, practices have been studied to get rid of this waste, such as recycling in the cement matrix, re-filling of the road, stabilization soil, stabilization/solidification processes, soil correction and as a liming agent [28].

On the other hand, 22,865 hectares of coconut were planted in Colombia in 2019 with a production of $145,578 \mathrm{t}$ /year. Since only the fruit is used, which is equivalent to $17 \%$ (endosperm), the remaining $83 \%$ is considered as waste (exocarp and mesocarp). The mesocarp is the most abundant part of the coconut fruit, which is treated as a reject product during its agro-industrial exploitation, from the cultivation of the raw material to its commercialization [29]. Thus, it would be generating tons of coconut waste per year, which causes a negative impact on the environment [30]. Thus, in this paper, the effect of adsorbent dosage and initial concentration on the removal of the azo-anionic dyes Congo Red and tartrazine present in synthetic aqueous solution was studied using adsorbents modified from coconut mesocarp. A kinetic and equilibrium study was carried out to identify the mechanisms involved in the adsorption process. The use of coconut mesocarp as adsorbent represents an economic advantage because it is an abundant residue in Colombian food industries; likewise, it is a biomass that has not been previously reported in the literature for the removal of diazoanionic dyes, such as tartrazine and Congo Red, due to the presence of lignin $(61.17 \% \mathrm{wt})$, cellulose $(21.18 \% \mathrm{wt})$ and hemicellulose $(17.64 \% \mathrm{wt})$ reported in its structure [31]. As well as cellulose, neither cellulose extracted from coconut mesocarp and modified with (CTAC) have been studied for this purpose, which is the reason why this work would be a contribution to current technology.

\section{Materials and Methods}

\subsection{Materials and Reagents}

To prepare, the following stock solutions were used: (Trisodium 1-(4-sulfonatophenyl)4-(4-sulfonatophenylazo)-5-pyrazolone-3-carboxylate) and Congo Red (naphthylensulfonic acid salt 3,3'-(4,4'- biphenylenebis (azo) bis (4amino) disodium), analytical grade. The $\mathrm{pH}$ was adjusted with $\mathrm{HCl}$ and $\mathrm{NaOH} 0.1 \mathrm{M}$. Cellulose modification was performed using $25 \%$ cetyl trimethyl ammonium chloride (CTAC).

\subsection{Experiment Design}

The dye adsorption capacity per biomass unit $(\mathrm{mg} / \mathrm{g})$ was considered as the response variable, the initial contaminant concentration $(\mathrm{mg} / \mathrm{L})$ and the adsorbent dose $(\mathrm{g} / \mathrm{L})$ as independent variables, and $\mathrm{pH}$, particle size, temperature and agitation rate as intervening variables. The experimental stage was carried out following a multilevel factorial design of 3 adsorbent dose levels $(5,8$ and $12 \mathrm{mg} / \mathrm{L})$, three variations of contaminant concentration $(40,70$, and $100 \mathrm{mg} / \mathrm{L})$. The anionic dyes tartrazine and Congo Red were removed, using the two biomaterials, for 36 experiments. A target was made with the unmodified biomasses and celluloses, in order to know the feasibility of cellulose synthesis and subsequent modification.

\subsection{Experimental Methodology}

\subsubsection{Mechanical Treatment of Biomass}

The coconut mesocarp was collected from street vendors. The material in the best condition was selected to take advantage of its long useful life, conserve its properties and avoid its early decomposition. The biomass was washed with deionized water, dried in an oven at $70{ }^{\circ} \mathrm{C}$ for $5 \mathrm{~h}$, and the size was reduced using a knife mill. The size classification 
was carried out in a Shaker type sieve utilizing a series of stainless steel sieves, which have the opening sizes $8,6.3,4.75,3.35,2.362,2,1.7,1.0,0.5$ and $0.355 \mathrm{~mm}$ [32].

\subsubsection{Cellulose Extraction}

Cellulose was extracted according to the method proposed by Xu et al. [33]. After mechanical pretreatment of the biomass, a double alkaline extraction was performed to eliminate the soluble polysaccharides. For this, $20 \mathrm{~g}$ of dry material was suspended in distilled water (up to have a solution between 2 to $4 \% w / v$ ) and mixed in a Waring mechanical mixer for $10 \mathrm{~min}$ at $300 \mathrm{rpm}$. The resulting sample was resuspended and filtered on a $75 \mu \mathrm{m}$ sieve. The liquid passing through the sieve was discarded, and $500 \mathrm{~mL}$ of $4 \%$ $\mathrm{NaOH}$ wt was added to the sediment. The suspension was shaken at $200 \mathrm{rpm}$ at $80{ }^{\circ} \mathrm{C}$ for $2 \mathrm{~h}$. The solid sample was washed with distilled water, and the extraction was repeated with $\mathrm{NaOH}$. After rewashing the sample, the liquid was discarded, and the resulting sediment was selected. For delignification, a solution of $50 \mathrm{~g}$ of $\mathrm{NaCl}$ to $500 \mathrm{~mL}$ of distilled water and $50 \mathrm{~mL}$ of glacial acetic acid was added to the sample obtained. The mixture was shaken for $24 \mathrm{~h}$. Subsequently, it was washed with distilled water, discarding the wash water. Finally, the resulting sample was dried at $70^{\circ} \mathrm{C}$ for approximately 2 to $3 \mathrm{~h}$, left to cool in a desiccator and reserved in plastic vials.

\subsubsection{Cellulose Quaternization}

The cellulose was modified with CTAC, using a ratio of per $1 \mathrm{~g}$ of cellulose a volume of $10 \mathrm{~mL}$ of cetyl at a concentration of $100 \mathrm{mmol} / \mathrm{L}$. It was left in agitation in the shaker for $24 \mathrm{~h}$ at $300 \mathrm{rpm}$. The quaternized sample was washed until reaching a neutral $\mathrm{pH}$ or close to 7 .

\subsubsection{Characterization of Bioadsorbents}

Coconut mesocarp (CM), coconut cellulose (CC) and modified coconut cellulose (MCC) were characterized by Fourier transform infrared spectroscopy (FTIR) analysis to identify the functional groups involved in the anion adsorption process, using a Perkin Elmer model 1600 series spectrophotometer. The surface structure was studied by scanning electron microscopy (SEM). The surface elemental composition was determined by energydispersive X-ray spectroscopy (EDS). SEM-EDS structural analysis was performed on a TESCAN model F E-MEB LYRA 3 scanning electron microscope with gold coating, $10 \mathrm{kV}$ voltage and $1 \mathrm{kx}$ magnification. The zero-loading point $\mathrm{pH}\left(\mathrm{pH}_{\mathrm{pzc}}\right)$, was determined to analyze the distribution of loads on the adsorbent surface and its effect on the adsorption capacity [34]. The cellulose sample obtained was characterized by thermogravimetry (TGA) and differential scanning calorimetry (DSC) to measure the material's stability to temperature changes.

\subsubsection{Adsorption Tests}

The adsorption experiments were performed according to the proposed design of experiments. Congo Red and tartrazine's synthetic solutions were placed in contact with the adsorbent in $5 \mathrm{~mL}$ test tubes, in an orbital shaker Thermo Scientific model MAXQ 4450 , with an agitation of $250 \mathrm{rpm}$, at room temperature, for $24 \mathrm{~h}$. The remaining concentration of Congo Red and tartrazine was determined by infrared spectrophotometry at 427 and $500 \mathrm{~nm}$, respectively, in a Biobase model BK-UV1900 UV/Vis spectrophotometer. The adsorption capacity of the bioadsorbent $\left(q_{t}\right)$ and the removal efficiency $(R)$ were determined with Equations (1) and (2):

$$
\begin{aligned}
& q_{t}\left[\frac{\mathrm{mg}}{\mathrm{g}}\right]=\frac{\left(C_{0}-C_{f}\right) V}{m} \\
& R[\%]=\frac{\left(C_{0}-C_{f}\right)}{C_{o}} * 100
\end{aligned}
$$


where $C_{0}\left(\frac{\mathrm{mg}}{\mathrm{L}}\right)$ is the initial dye concentration in the dissolution, $C_{f}\left(\frac{\mathrm{mg}}{\mathrm{L}}\right)$ is the final concentration of dye in the dissolution, $V(\mathrm{~L})$ is the volume of dissolution and $m(\mathrm{~g})$ is the mass of bioadsorbent used in the tests.

\subsection{Adsorption Isotherms}

Adsorption isotherms describe adsorbate-adsorbent interactions, a critical factor in optimizing the use of adsorbents [35]. The tests for the determination of the isotherms were carried out by varying the initial concentration of the sample $(25,50,75,100$ and $125 \mathrm{mg} / \mathrm{L})$, at the best experimental conditions of adsorbent dosage using the bioadsorbents prepared from coconut mesocarp, for $24 \mathrm{~h}$ at $150 \mathrm{rpm}$ and room temperature. The experimental data were fitted to the Langmuir (3), Freundlich (4) and Dubinin-Radushkevich (5) models, shown in Table 1.

Table 1. Adsorption isotherm models.

\begin{tabular}{|c|c|c|}
\hline Model. & Equation & Parameters \\
\hline Langmuir & $q_{e}=\frac{q_{\max } b C_{e}}{1+b C_{e}}(3)$ & $\begin{array}{c}q_{\max }(\mathrm{mg} / \mathrm{g}): \text { maximum amount of analyte removed per unit weight of biomass } \\
b(\mathrm{~L} / \mathrm{mg}): \text { constant related to the affinity of the binding sites with the contaminant } \\
C_{e}(\mathrm{mg} / \mathrm{L}) \text { : concentration of the remaining contaminant in solution }\end{array}$ \\
\hline Freundlich & $q_{e}=k_{F} C_{e}^{\frac{1}{n}}(4)$ & $\begin{array}{c}k_{F}\left(\mathrm{mg} / \mathrm{g}(\mathrm{L} / \mathrm{mg})^{1 / \mathrm{n}}\right) \text { : adsorption capacity indicator } \\
n \text { : indicates the effect of concentration on adsorption capacity and represents the } \\
\text { adsorption intensity. }\end{array}$ \\
\hline $\begin{array}{c}\text { Dabunin- } \\
\text { Radushkevich }\end{array}$ & $\begin{array}{c}q_{e}=q_{D R} * e^{-K_{D R} \varepsilon^{2}}(5) \\
\varepsilon=R T * \ln \left(1+\frac{1}{C_{e}}\right)(6) \\
E=\frac{1}{\sqrt{2 K_{D R}}}(7)\end{array}$ & $\begin{array}{l}\varepsilon^{2}: 1 \text { Polanyi's potential which is based on temperature } \\
K_{D R}\left(\mathrm{~mol}^{2} / \mathrm{kJ}^{2}\right) \text { : Dubinin-Radushkevich constant related to adsorption energy } \\
E(\mathrm{~kJ} / \mathrm{mol}) \text { : average adsorption energy per molecule of adsorbate required to } \\
\text { transfer one mole of the ion from the solution to the adsorbent surface }\end{array}$ \\
\hline
\end{tabular}

\subsection{Adsorption Kinetics}

The kinetic study was carried out to study the effect of time on removal and the possible mechanisms involved in the process. Thus, tests were performed at the best conditions of adsorbent dose and initial dye concentration at $150 \mathrm{rpm}$ and room temperature. Aliquots were taken at different time intervals $(5,10,20,30,30,60,60,120,240,480$, 720 and $1440 \mathrm{~min}$ ), and the remaining dye concentration was determined. The experimental data were fitted to the pseudo-first-order (8), pseudo-second-order (9), Elovich (10) and intraparticle diffusion (11) models, summarized in Table 2.

Table 2. Kinetic models.

\begin{tabular}{|c|c|c|}
\hline Model & Equation & Parameters \\
\hline Pseudo-first-order & $q_{t}=q_{e 1}\left(1+e^{-k t}\right)$ & $\begin{array}{c}k_{1}\left(\mathrm{~min}^{-1}\right): \text { Lagergren's kinetic constant } \\
q_{e 1}(\mathrm{mg} / \mathrm{g}): \text { adsorption capacity at equilibrium. } \\
q_{t}(\mathrm{mg} / \mathrm{g}): \text { adsorption capacity at time } \mathrm{t} \\
\mathrm{t}(\mathrm{min}) \text { : time }\end{array}$ \\
\hline Pseudo-secon -order & $q_{t}=\frac{q_{e}^{2} k_{2} t}{1+k_{2} q_{e} t}(9)$ & $\begin{array}{c}k_{2}(\mathrm{~g} / \mathrm{mg} \cdot \mathrm{min}): \text { pseudo-second order kinetic constant } \\
q_{e 2}(\mathrm{mg} / \mathrm{g}): \text { adsorption capacity at equilibrium. } \\
q_{t}(\mathrm{mg} / \mathrm{g}): \text { adsorption capacity at time } \mathrm{t} \\
\mathrm{t}(\mathrm{min}) \text { : time }\end{array}$ \\
\hline Elovich & $\begin{array}{c}q_{t}=\frac{1}{\beta} \ln (t)+\frac{1}{\beta} \ln (\alpha \beta) \\
(10)\end{array}$ & $\begin{array}{c}q_{t}(\mathrm{mg} / \mathrm{g}) \text { : adsorption capacity at time } \mathrm{t} \\
\alpha\left(\mathrm{mg} / \mathrm{g} \cdot \mathrm{min}^{-1}\right) \text { : initial adsorption rate } \\
\beta(\mathrm{g} / \mathrm{mg}) \text { : desorption constant related to the surface area of the biomaterial }\end{array}$ \\
\hline Intraparticle diffusion & $q_{t}=k_{3} t^{1 / 2}(11)$ & $\begin{array}{c}q_{t}(\mathrm{mg} / \mathrm{g}): \text { adsorption capacity at time } \mathrm{t} \\
\mathrm{t}(\mathrm{min}): \text { time } \\
k_{3}\left(\mathrm{mg} / \mathrm{g} \cdot \mathrm{min}^{1 / 2}\right): \text { kinetic constant of intra-particle diffusion }\end{array}$ \\
\hline
\end{tabular}




\section{Results and Discussion}

\subsection{Characterization of Biomaterials \\ 3.1.1. TGA and DSC Analysis}

The thermogravimetric analysis provides information on the composition of a sample. It monitors its performance concerning temperature in a specific atmosphere, recording the sample's weight loss when exposed to a combination of temperature, heating rate and reaction atmosphere [33]. Figure 1 shows the TGA and DSC analysis of cellulose extracted from coconut mesocarp. A decrease of about $9.65 \%$ in coconut mesocarp cellulose weight was observed between $75^{\circ} \mathrm{C}$ and $140{ }^{\circ} \mathrm{C}$, which is due to the moisture content present in the experimental sample. About $50 \%$ of mass loss was associated with hemicellulose and lignin's corresponding degradation at temperatures ranging from $180^{\circ} \mathrm{C}$ to $340{ }^{\circ} \mathrm{C}$ [38]. Subsequently, from $340^{\circ} \mathrm{C}$ onwards, cellulose degradation occurs, with the degradation of $33.4 \% \mathrm{w}$. Between 400 and $600{ }^{\circ} \mathrm{C}$, there is no significant decrease in mass in the sample, which is attributed to the absence of degradable non-cellulosic substances such as lignin and the possible presence of stable oxides at high temperatures $[38,39]$.
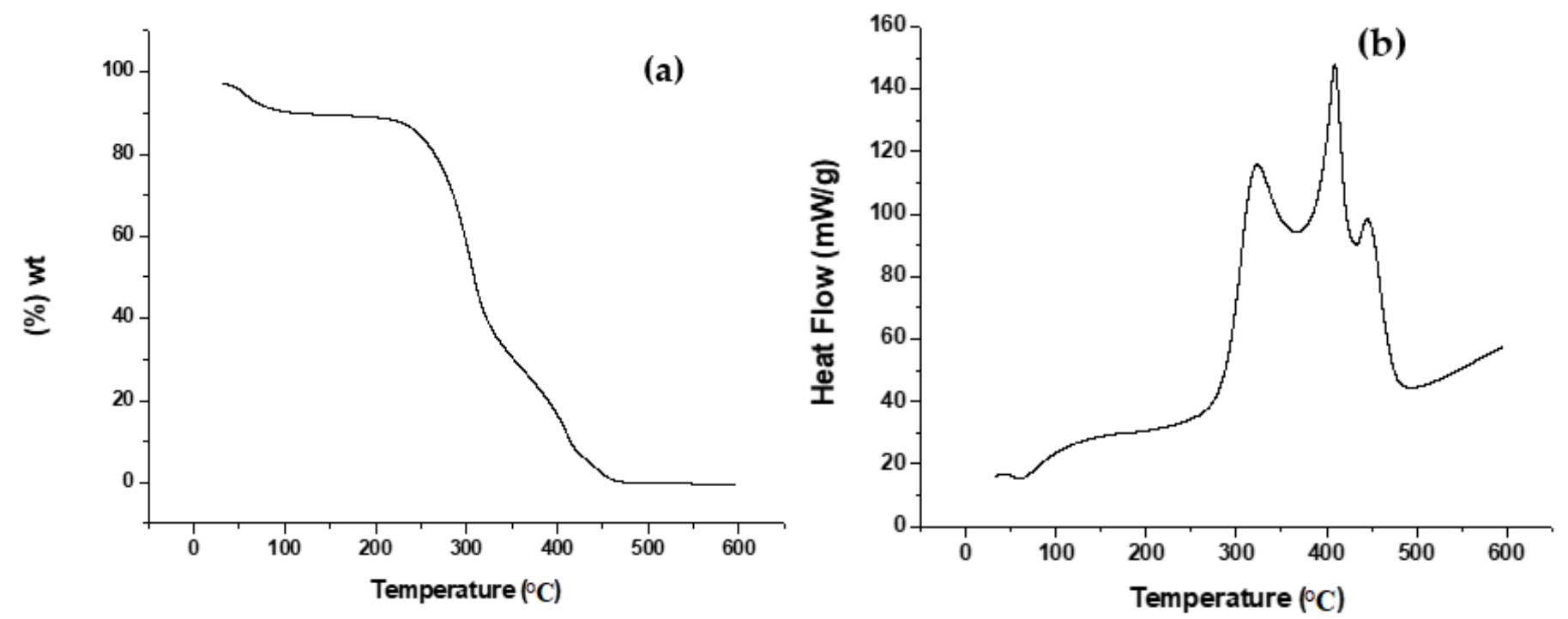

Figure 1. Analysis (a) TGA and (b) DSC of the cellulose extracted from the CM.

DSC shows that the celluloses obtained present an endothermic peak around $80^{\circ} \mathrm{C}$ associated with water evaporation. From 320 to $350^{\circ} \mathrm{C}$, an exothermic pyrolysis reaction peak occurred, corresponding to the melting of the cellulose polymer crystals. It could be attributed to the different reactions or mechanisms involved in the pyrolysis of the three components. Previously, it has been indicated that the carbonization process was highly exothermic, while the volatilization was endothermic [40]. The non-occurrence of a peak between $222-228^{\circ} \mathrm{C}$ means that hemicellulose was removed during the cellulose extraction process from the coconut mesocarp [41].

\subsubsection{FTIR Spectroscopy Analysis}

FTIR transmittance spectra for CC and MCC, before and after tartrazine removal, are shown in Figure 2. The position of the peak and the corresponding chemical functional group assignments are summarized in Table 3.

The IR spectra of the CC (Figure 2a) and MCC (Figure 2b) show the presence of functional groups involved in the uptake of pollutants during the adsorption processes. The presence of $\mathrm{CH}$ vibrations, the intensity reaching a maximum close to $900 \mathrm{~cm}^{-1}$ for CC and $890 \mathrm{~cm}^{-1}$ for MCC, indicates the purity of cellulose, which is a common characteristic of synthesized adsorbents [42]. The peak near $1455 \mathrm{~cm}^{-1}$ indicates the $\mathrm{O}-\mathrm{H}$ bending vibration of the cellulose. Bands at 3450 and $3390 \mathrm{~cm}^{-1}$ refer to the $\mathrm{O}-\mathrm{H}$ stretch and at $2937 \mathrm{~cm}^{-1}$ to 
the C-H stretch; both groups present in cellulose. There was a significant increase in peak strength at $890 \mathrm{~cm}^{-1}, 1460 \mathrm{~cm}^{-1}, 2937 \mathrm{~cm}^{-1}$ and $3390 \mathrm{~cm}^{-1}$, after surface modification with CTAC. Likewise, the bands that were observed in the transmittance spectra corresponding to the stretching close to $1100 \mathrm{~cm}^{-1}$, increased significantly after the chemical treatment process, due to the stretching vibration of the pyranose ring of C-O-C [43]. The band centered at $1472 \mathrm{~cm}^{-1}$ is attributed to the $\mathrm{C}_{6} \mathrm{H}_{6}-\mathrm{Cl}^{+}$symmetric deformation modes of the CTAC head group, which confirms that this group successfully bound to the extracted cellulose. For this reason, the MCC has a large number of alkyl chains CTAC. Similar information was reported when preparing a cetyltrimethylammonium bromide (CTAB) -graphene oxide biocomposite [44].
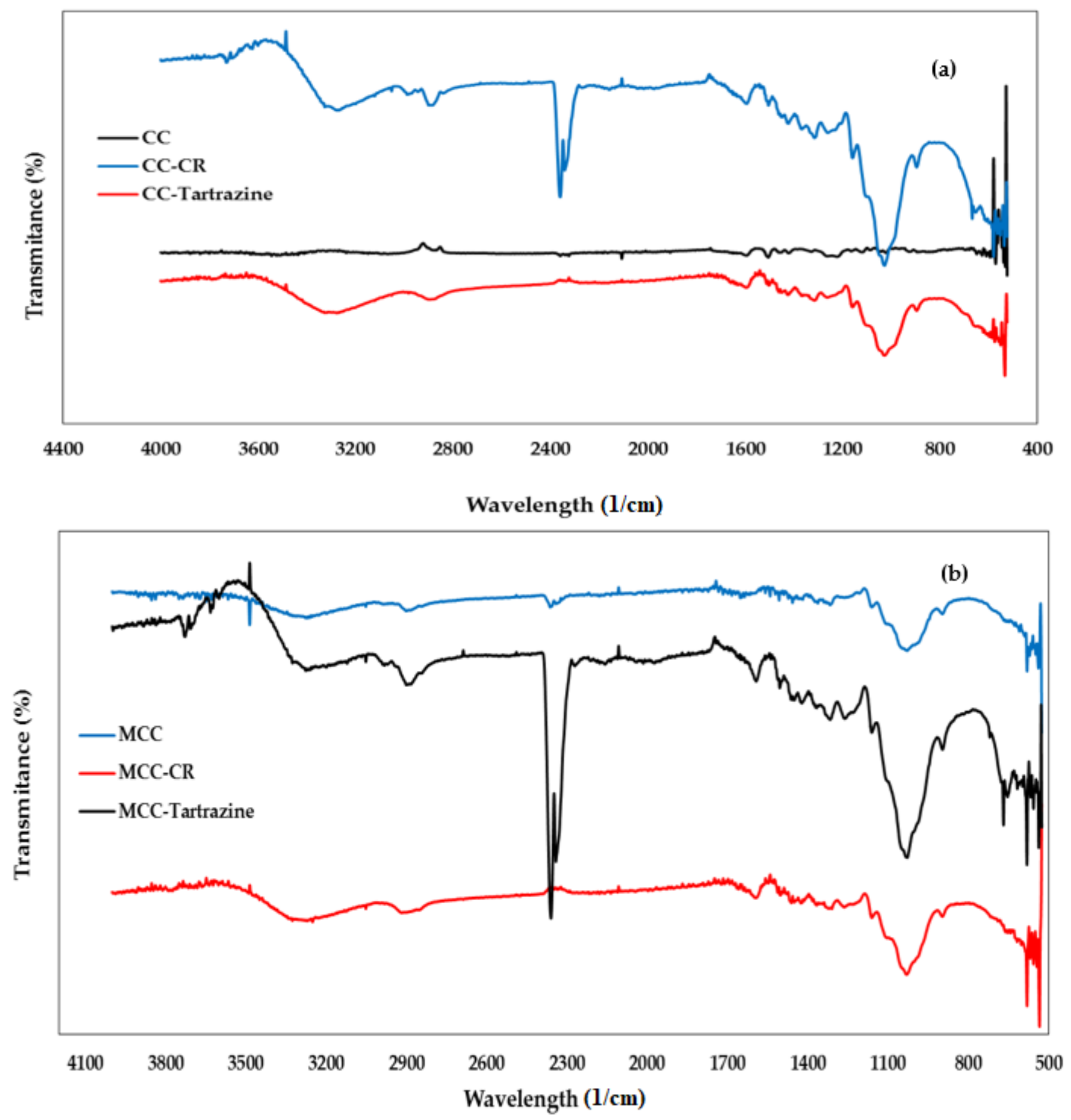

Figure 2. IR spectra of (a) CC and (b) MCC before and after removal of CR and tartrazine. 
Table 3. Peak position and chemical group assignments in the CC and MCC.

\begin{tabular}{|c|c|c|c|}
\hline \multicolumn{2}{|c|}{ Peak (Wavelength $\mathrm{cm}^{-1}$ ) } & \multirow{2}{*}{ Functional Group } & \multirow{2}{*}{ Chemical Component } \\
\hline $\mathrm{CC}$ & MCC & & \\
\hline 3450 & 3390 & Stretching $-\mathrm{OH}$ & Cellulose \\
\hline 2937 & 2937 & Stretching $-\mathrm{CH}$ & Cellulose \\
\hline 2275 & 2337 & Stretching $-\mathrm{C}=\mathrm{O}$ & Cellulose \\
\hline 1720 & 1691 & Stretching $-\mathrm{C}=\mathrm{C}$ & Hemicellulose \\
\hline 1640 & 1640 & Vibration $\mathrm{N}=\mathrm{N}$ & Lignin \\
\hline 1455 & 1455 & Bending vibration $-\mathrm{OH}$ & Cellulose \\
\hline- & 1472 & Symmetric deformation of $\mathrm{C}_{6} \mathrm{H}_{6}-\mathrm{Cl}$ & CTAC \\
\hline 1100 & 1100 & Stretching $\mathrm{C}-\mathrm{O}-\mathrm{C}$ & Polysaccharides \\
\hline 900 & 890 & Vibration $-\mathrm{CH}$ & Cellulose \\
\hline
\end{tabular}

The peaks observed at $1720 \mathrm{~cm}^{-1}$ and $1621 \mathrm{~cm}^{-1}$ were related to the $\mathrm{C}=\mathrm{O}$ stretching of the acetyl and uronic ester groups of hemicellulose [45]. After the removal of CR and tartrazine, the enlargement and shift of specific bands was evidenced in both bioadsorbents. Using MCC, pronounced peaks are observed at 2357 and $1035 \mathrm{~cm}^{-1}$, attributed to the fixation of the dye at these sites on the surface of the bioadsorbents [46]. Similarly, the bands at 3432 and $1631 \mathrm{~cm}^{-1}$ decrease in amplitude and move slightly when CR is adsorbed, indicating a deep involvement of the amino species. On the other hand, the conservation of the pattern in the FTIR spectrum implies the non-biodegradability of the CC and MCC sample after the adsorption of the dyes [47]. The intensification of the peak near $1250 \mathrm{~cm}^{-1}$ after adsorption of $\mathrm{CR}$ and tartrazine can be attributed to the $-\mathrm{SO}_{3}$ group in the dyes as previously reported by Kumar et al. [48].

\subsubsection{SEM-EDS Structural Analysis}

SEM analysis of the coconut mesocarp (Figure 3a), exhibits the structure of fibrous lignocellulosic materials; the CM shows an irregular exposed area with the presence of fiber fragments, blocks with noticeable and irregular circular indentations, heterogeneous spirals, fragments embedded square grids and heterogeneous spirals. The appearance of fiber fragments is due to the presence of lignin $(61.17 \% \mathrm{wt})$, cellulose $(21.18 \% \mathrm{wt})$ and hemicellulose $(17.64 \% \mathrm{wt})$ in the structure of the bioadsorbent, which benefits the adsorptive capacities of the material due to the presence of carboxyl, amino and hydroxyl functional groups, which have the ability to retain $\mathrm{Pb}$ (II) ions with the formation of complexes [49].

Figure $3 \mathrm{~b}$ shows the cellulose extracted from the coconut mesocarp (CC), which shows the presence of porous cavities that are attributed to the delignification of the biomass [50]. The EDS spectrum shows that the elements with the highest presence in CC are carbon $(55.43 \% \mathrm{w})$ and oxygen $(43.01 \% \mathrm{w})$, with small traces of sodium $(0.65 \% \mathrm{w})$ and chlorine $(0.92 \% \mathrm{w})$; the disappearance of silicon and calcium, due to $\mathrm{NaOH}$ treatment, is necessary for the elimination of lignin and hemicelluloses from the CM [50]. After modification with CTAC (Figure 3c), it is observed the softening of the adsorbent surface and an increase in the porosity, thus in the physicochemical properties of the biomaterial [51]. Although, it is appreciated that a change in the exposed surface of the material after the modification, thus increasing the roughness of the material, and the smoothing of the surface due to the dissolution of impurities [52], EDS does not evidence that this has been successful; an increase in the presence of carbon $(61.48 \% \mathrm{w})$ and a decrease in the amount of oxygen $(38.28 \% \mathrm{w})$ and traces of aluminum $(0.24 \% \mathrm{w})$ in the $1.5 \mathrm{keV}$ intensity peak. Similar behavior was found when modifying a magnetic biochar with cetyl trimethyl ammonium bromide, finding that there is no evidence of this modification's presence in the EDS spectrum [53]. 

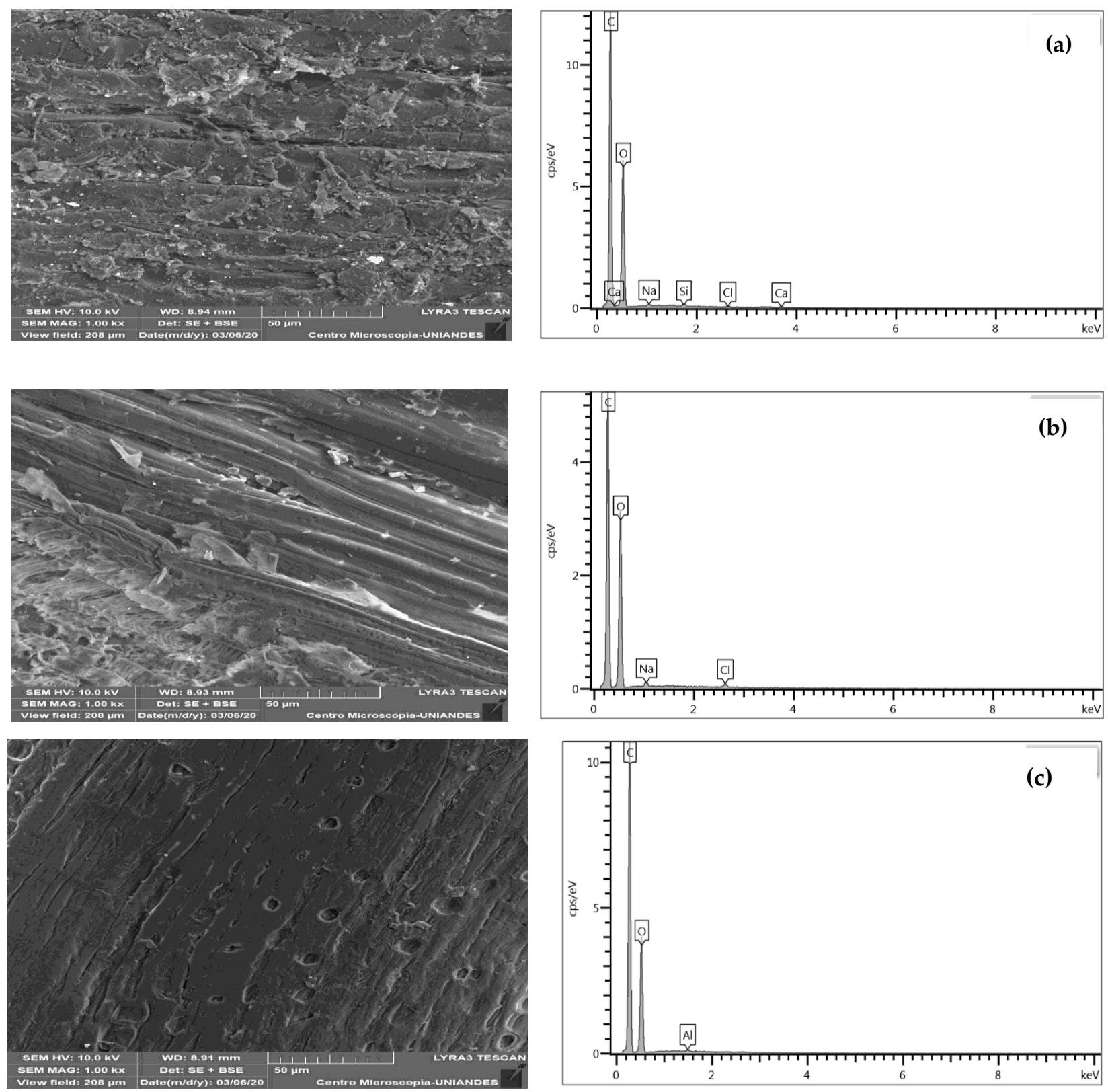

Figure 3. SEM micrographs and EDS spectra of (a) CM, (b) CC and (c) MCC.

\subsubsection{Zero Load Point $\mathrm{pH}$}

Considering that bioadsorbents behave as a positively charged matrix at $\mathrm{pH}$ values below $\mathrm{pH}_{\mathrm{pzc}}$, and if the solution's $\mathrm{pH}$ is increased, it would be negatively charged by the surface functional groups' deprotonation. It would reject the interaction with anionic dyes under study by electrostatic forces [54]. For CC it was found that the $\mathrm{pH}_{\mathrm{pzc}}$ was 5.88 while for MCC it was 5.73. Therefore, an operating $\mathrm{pH}$ of 4 was decided for both dyes, to have a positively charged surface. $\mathrm{A} \mathrm{pH}_{\mathrm{pzc}}$ of 6.8 has been reported for coconut Shell [55], 5.6 for coconut mesocarp and epicarp [56] and 6.7 for babassu coconut mesocarp [57,58]; there is a slight variation between the adsorbents prepared in the present study and the previously reported coconut mesocarp and epicarp.

\subsection{Effect of Adsorbent Dosage and Initial Concentration}

The adsorbent dose is an essential parameter in adsorption processes because it influences the number of active sites available for contaminants' adsorption [22]. On the other hand, the initial solute concentration acts as a driving force of the adsorption process, 
favoring the diffusive and mass transfer processes from within the solution (with a higher amount of dye) to the free surface of the adsorbent [59]. From the CR and tartrazine removal tests carried out as a standard, it was found that coconut mesocarp is a good adsorbent of CR, reaching removal percentages between 83 and 97\%, with adsorption capacities ranging from 3.3 to $13.01 \mathrm{mg} / \mathrm{g}$. In comparison, the removal percentages of tartrazine ranged from 0.1 to $5.6 \%$, observing that the increase of the initial concentration favors the removal. The performance of the raw material against tartrazine could be due to the negative charge of the biomaterial due to the presence in its structure of hydroxyl, carbonyl and carboxyl groups (present in lignocellulosic materials), which have negative charges and would repel the interactions between the dye and the active centers, decreasing the efficiency and adsorption capacity.

This shows the need to modify the structure of lignocellulosic biomaterials to increase the dyes' efficiency and adsorption capacity under study. Thus, Figure 4 shows the effect of the adsorbent dose and initial concentration on $\mathrm{CR}$ and tartrazine's removal capacity on CC and MCC.
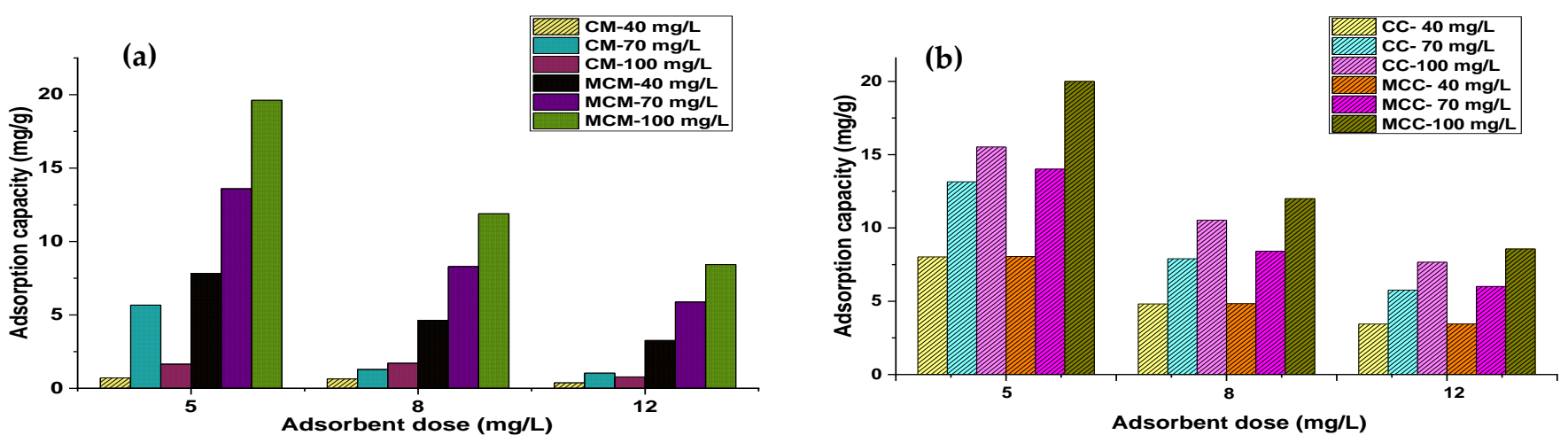

Figure 4. Effect of adsorbent dose and initial concentration on the adsorption capacity of (a) tartrazine and (b) Congo Red.

When using CC and MCC to remove CR and tartrazine, it is observed that decreasing the adsorbent dose increases the adsorption capacity. The decrease in the amount of adsorbed dye $q_{e}(\mathrm{mg} / \mathrm{g})$ with increasing adsorbent mass is due to the splitting in the flux or concentration gradient between the solute concentration in solution and the solute concentration at the adsorbent surface [60]. The increase in adsorbent mass leads to a rise in the percentage removal of both dyes, and this is due to the increase in active sites on the adsorbent surface by the amount of adsorbent available.

On the other hand, it was found that the higher the initial concentration, results in higher adsorption capacity, except when $5 \mathrm{mg} / \mathrm{L}$ and $12 \mathrm{mg} / \mathrm{L}$ were used to remove tartrazine, with much higher performance by the modified cellulose. This is because a higher concentration provides a driving force to overcome all the resistances of the anionic dye between the aqueous and solid phases, thus increasing adsorption; moreover, as the initial concentration increased, so did the number of collisions between the dye ions and the adsorbent, thus improving the adsorption process [61]. Results similar to those of the present study have been previously reported, when evaluating different initial concentrations tested (300, 500 and $700 \mathrm{mg} / \mathrm{L})$, the increase in the adsorbent mass from 0.2 to $1.0 \mathrm{~g}$ results in a decrease in the capacity of adsorption of the dye from $691.4 \mathrm{mg} / \mathrm{g}$ to $295.9 \mathrm{mg} / \mathrm{g}$ [28]. The abovementioned was explained, because at high doses of adsorbent the agglomeration of adsorbent particles can occur, which results in a decrease in both the specific surface area and the number of active sites, and consequently an increase in the length of the diffusion path from the adsorbent surface to the pores [62]. Likewise, the increase in the adsorbent mass causes an increase in the adsorption sites available for the adsorbate molecules, which results in a lower saturation and a lower adsorption capacity [63]. Therefore, it is evident that at lower doses of CC and MCC there is a more efficient use of their available active adsorption sites, which leads to a higher dye 
load [64]. It is important to note that, when using the 25 and $35 \mathrm{mg}$ doses of material, the concentration of both CR and tartrazine remains the same, which promotes less use of the sites.

Figure 4 evidenced the selectivity of the biomaterials for CR at the different concentrations evaluated; this was due to the reactive nature of the dye since it easily sticks to any type of fibrous material, according to what was reported by [65]. Similarly, when using MCC, a significant improvement in the removal capacity of both pollutants was obtained, with removal percentages $>90 \%$ in all cases. When using babassu epicarp to remove the anionic dyes Remazol blue R160 (BR 160), ruby S2G (R S2G), Remazol red 5R (RR 5), Remazol purple 5R (VR 5) and indanthrene olive green (IOG), adsorption capacities between 3.44 and 0.32 were obtained, showing a behavior to remove dyes that gave the ordered set BR $160>$ VR $5>$ RR $5>$ R S2G > IOG [58].

\subsection{Adsorption Equilibrium}

Adsorption isotherms reflect the process in which the analyte that binds to the sorbent is in a state of equilibrium with the ionic species that remain dissolved in the solution. Isotherms represent the adsorption equilibrium, which is the ratio between the amount adsorbed and the equilibrium pressure or concentration at a constant temperature [36]. The experimental data were fitted to the Langmuir, Freundlich and Dubinin-Radushkevich models (Figure 5) to identify the mechanisms of contaminant removal [16]. The fitting parameters are presented in Table 4.
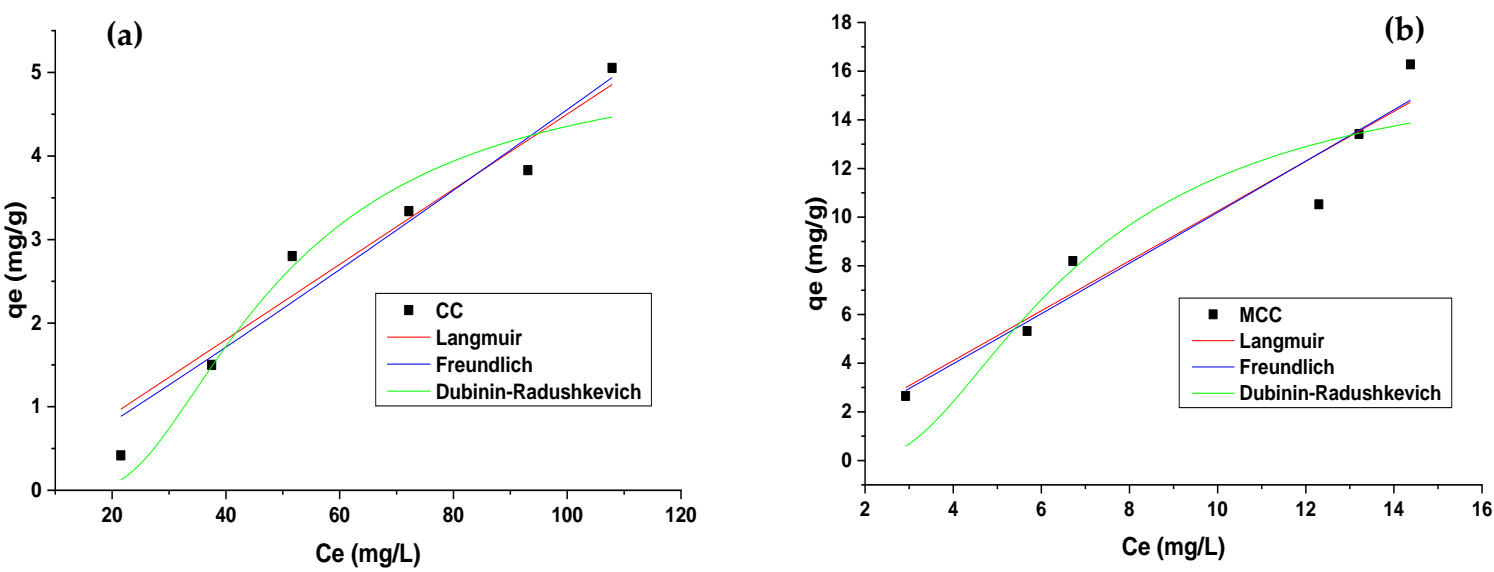

(c)
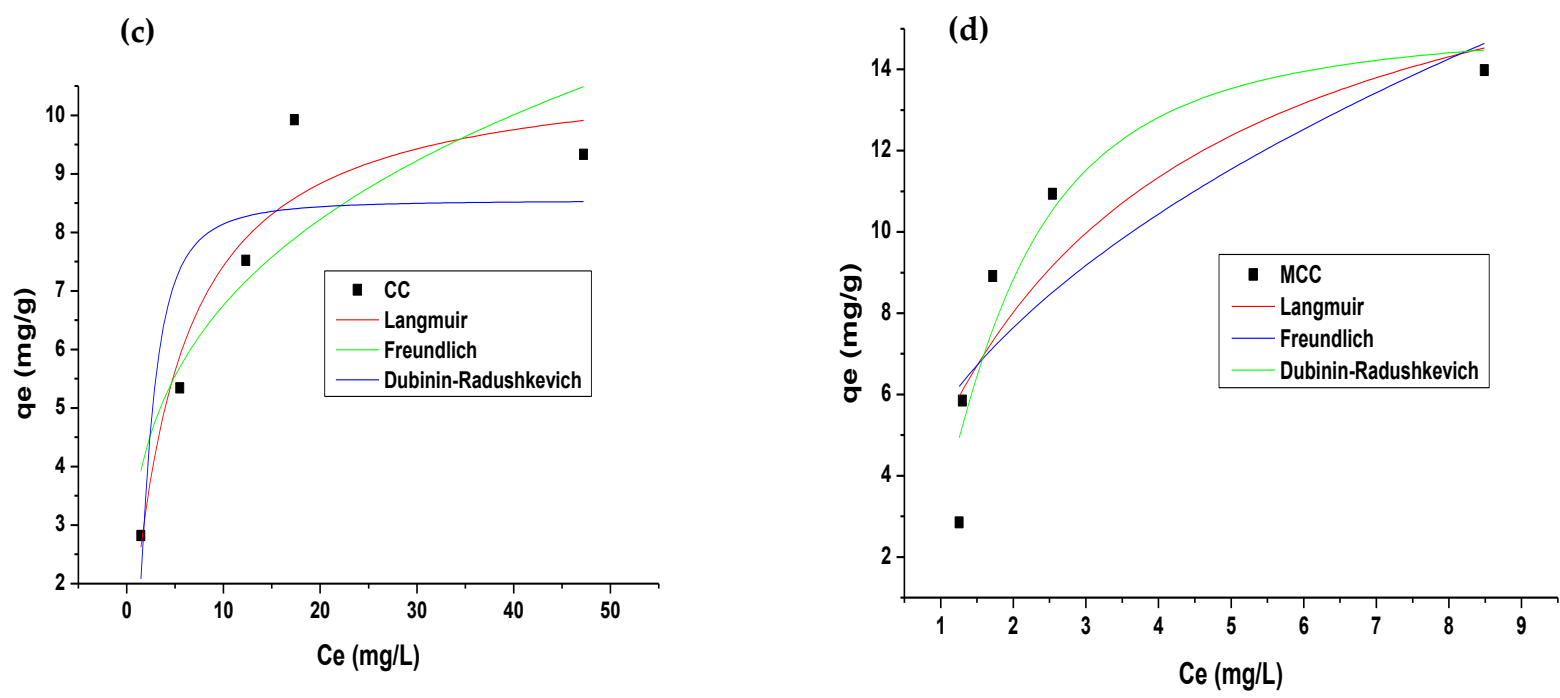

Figure 5. Fitting to adsorption isotherm models of (a) tartrazine on CC, (b) tartrazine on MCC, (c) Congo Red on CC and (d) Congo Red on $\mathrm{MCC}$, at $\mathrm{pH} 4,30^{\circ} \mathrm{C}$ and $5 \mathrm{mg} / \mathrm{L}$ of adsorbent dose. 
Table 4. Adsorption isotherm parameters.

\begin{tabular}{|c|c|c|c|c|c|}
\hline \multirow{2}{*}{ Model } & \multirow{2}{*}{ Parameters } & \multicolumn{2}{|c|}{ Tartrazine } & \multicolumn{2}{|c|}{ Congo Red } \\
\hline & & $\mathrm{CC}$ & MCC & $\mathrm{CC}$ & MCC \\
\hline \multirow{4}{*}{ Langmuir } & $q_{\max }(\mathrm{mg} / \mathrm{g})$ & 5.222 & 18.412 & 10.890 & 19.372 \\
\hline & $b(\mathrm{~L} / \mathrm{mg})$ & $2.0967 \times 10^{-5}$ & $1.220 \times 10^{-4}$ & 0.215 & 0.353 \\
\hline & $R^{2}$ & 0.933 & 0.914 & 0.899 & 0.722 \\
\hline & $S S$ & 12.120 & 0.022 & 1.219 & 5.632 \\
\hline \multirow{4}{*}{ Freundlich } & $k_{F}\left(\mathrm{mg} / \mathrm{g}(\mathrm{L} / \mathrm{mg})^{1 / \mathrm{n}}\right)$ & 0.033 & 0.956 & 3.516 & 5.598 \\
\hline & $n$ & 0.937 & 0.973 & 3.527 & 2.224 \\
\hline & $R^{2}$ & 0.936 & 0.915 & 0.732 & 0.629 \\
\hline & $S S$ & 0.177 & 0.646 & 2.236 & 2.219 \\
\hline \multirow{5}{*}{$\begin{array}{l}\text { Dubinin- } \\
\text { Radushkevich }\end{array}$} & $q_{D R}(\mathrm{mg} / \mathrm{g})$ & 5.214 & 16.512 & 8.544 & 15.072 \\
\hline & $K_{D R}\left(\mathrm{~mol}^{2} / \mathrm{kJ}^{2}\right)$ & $2.441 \times 10^{-4}$ & $5.181 \times 10^{-6}$ & $7.106 \times 10^{-7}$ & $4.3683 \times 10^{-7}$ \\
\hline & $E(\mathrm{KJ} / \mathrm{mol})$ & 45.229 & 310.65 & 838.83 & 1069.86 \\
\hline & $R^{2}$ & 0.933 & 0.834 & 0.683 & 0.879 \\
\hline & SS & 0.464 & 2.129 & 0.914 & 1.506 \\
\hline
\end{tabular}

From the results of tartrazine adsorption on CC (Figure 5a) and MCC (Figure 5b), and the parameters in Table 4, it can be said that the model that best fits the process was Freundlich, having a slight variation concerning those of Langmuir and DubininRadushkevich; this indicated that the process happens with the presence of mono and multilayers, due to the heterogeneity of the active centers of the two adsorbents. However, chemical forces prevail over these, and the formation of multilayers limits the process, with a non-uniform distribution of heat and adsorption affinities on the heterogeneous surface [35]. The active absorption sites are first occupied by strong bonds, and this strength decreases as they are occupied by ions [35]. The $k_{f}$ is higher when adsorption of the dye on MCC occurs, indicating its higher selectivity for tartrazine than CC. The Freundlich constant $n$ (Table 3) values are not in the range 1-10, indicating that the chemical bonds formed between the ions and the adsorbent are weak; this could be due to the importance of the formation of a monolayer during adsorption [66]. The E parameter of the Dubinin-Radushkevich model is higher for MCC $(310.65 \mathrm{KJ} / \mathrm{mol})$ than CC $(42.229 \mathrm{KJ} / \mathrm{mol})$, indicating that the ion exchange process is more elevated in modified cellulose than in natural cellulose [35]. It has been previously reported for the removal of tartrazine that the Freundlich model is the one that best describes the process, using bentonite modified with hexadecyltrimethylammonium bromide [23] and activated carbon from Lantana camara [1]; while the use of activated carbon from Moringa [25] was found in Langmuir to be a better fitting.

On the other hand, the adsorption isotherms of CR showed better fitting to the Langmuir model when CC was used, while Dubininin-Radushkevich described the equilibrium on MCC. The equilibrium of removal of CR on CC and MCC show an important adsorption even at low concentrations, with an H-type isotherm in the Giles classification; this indicates the predominance of strong ionic interactions between the adsorbate-adsorbent [67]. The fit to the Langmuir model suggests that the adsorption process occurs in a monolayer with similar activation energy in all the active centers [1]. From the Langmuir parameter $b$, it can be intuited that the MCC presented greater affinity for the pollutant, the values of $b$ ranged between 0 and 1, which indicates favorability of the process; as well as a greater adsorption capacity according to the $q_{\max }$ [15]. Similarly, the parameter $n$ of the Freundlich model suggests a high affinity by $C C$ and MCC for the $C R$, since in both cases, it is $>1$ [1]. Values below $8 \mathrm{~kJ} / \mathrm{mol}$ represent the process's physical nature, while values between 8 and $16 \mathrm{~kJ} / \mathrm{mol}$ indicate that the process was chemical [35]. The data provided 
in Table 3 showed that the adsorption process of CR on CC $(838.83 \mathrm{~kJ} / \mathrm{mol})$ and MCC $(1069.86 \mathrm{~kJ} / \mathrm{mol})$ occurred due to chemical interactions, involving the functional groups and electron transfer between the adsorbate and the adsorbents. Previously, it was reported that the adsorption isotherm of the azo dye on nanostructures obtained from broom and straw [20].

Table 5 shows data of the Langmuir parameter $q_{\max }$, reported for the removal of tartrazine and Congo Red with adsorbents of different nature. It is observed that the adsorption capacity of tartrazine was lower for the other adsorbents, with respect to CR, and that the results obtained in the present study are in the average for lignocellulosic biomaterials; the best results were obtained using the chitosan/polyaniline matrix [59], zeolites and different activated carbons such as corn and moringa seeds. This is due to the large surface area of this kind of adsorbent, especially after chemical and/or thermal modification. The removal of $\mathrm{CR}$ also presented average adsorption capacities for lignocellulosic materials, following what has been reported in the literature, with especially outstanding performance of biochars, zeolites [22] and the exchange membrane made from eggshells [68].

\subsection{Adsorption Kinetics}

Adsorption kinetics was studied to identify the steps that control the adsorption mechanism and the incidence of time on the process [37]. In removing tartrazine and CR, a better performance was observed for the cellulose modified with CTAC, showing the success of the modification process with the quaternary salt. Similarly, it was found that the equilibrium time was reached at about $30 \mathrm{~min}$ (Figure 6) and that initially, the removal of the dyes was rapid, removing approximately $97 \%$ of the contaminant in the first $5 \mathrm{~min}$, which could be due to the high availability of active centers in the unsaturated material, as well as the availability of anions [75]. These results differ from those reported on the removal of CR on reticulated cellulose-chitosan foam, where adsorption was found to increase rapidly at $8 \mathrm{~h}$ and then continued gradually over $120 \mathrm{~h} \mathrm{[78].} \mathrm{However,} \mathrm{in} \mathrm{the}$ removal of tartrazine on Lantana camara [1] and Congo Red on silica-rich zeolite particles functionalized with $\mathrm{ZnO}$ [22], that the kinetics was rapid in the initial stages of removal as in the present study.

The study of kinetic models enables the quantitative understanding of the adsorption process because it helps describe the process [70]. In the present study, pseudo-firstorder [25], pseudo-second-order [19], Elovich [79] and Intraparticle Diffusion kinetic models were applied [68] to study the adsorption mechanism of Congo Red and tartrazine dyes. According to the results presented in Table 6, it can be said that the kinetics of tartrazine on CC presented a low fitting to the evaluated models, Elovich is the one that came closest to the experimental data $\left(R^{2}=0.756\right)$. On the other hand, when using MCC, the Elovich $\left(R^{2}=0.987\right)$ and pseudo-second-order $\left(R^{2}=0.999\right)$ models fit the kinetics well. The fitting to these models explains the chemisorptive elimination of the tartrazine dye. In addition, the experimental value $\left(q_{e}\right)$ when using MCC is close to the calculated value, as a sign of the good fit of the data to the models, which is not the case with CC. The parameter $\alpha$ of the Elovich model was higher in CC than in MCC, suggesting that the reduction in adsorption rate with increasing amount adsorbed is greater in CC than in MCC, in agreement with that reported by Marques et al. [80], by using Attalea funifera fibers.

On the other hand, the kinetics of CR over CC was fitted by the pseudo-first-order, pseudo-second-order and Elovich model with $R^{2}>0.98$ in all cases; while when using MCC the four evaluated models present $R^{2}=0.99$ in all cases, as shown in Table 6. As with tartrazine, the Elovich and pseudo-second-order models fitting assumes that the nature of the adsorption process has a chemical nature [28]. The values of $\alpha$ suggests that adsorption occurred rapidly in the initial minutes (Figure $5 b$ ), while the value recorded for $\beta$ indicates that in this system, desorption can be easily achieved, facilitating the recovery of the biomaterial and the colorant [80]. Moreover, the value of the $\mathrm{k}_{3}$ parameter of the intraparticle diffusion model suggests that the diffusion rate during the process was high. 
Since the graph does not cut the origin, the model proposes that diffusion is not the limiting step, and that it happens in several stages: In the first few minutes occurs the surface adsorption or transport of CR molecules from the bulk phase to the adsorbent surface. Then, intraparticle diffusion of CR anions into the pores of the adsorbent particles occurs. Finally, the equilibrium stage showed gradual adsorption dominated by porous diffusions. Therefore, diffusion between particles intervened in the adsorption process, but cannot control CR molecules' overall adsorption [81]. Consequently, more than one mechanism could drive the adsorption mechanism, including surface and pore diffusion [79]. The adsorption rate constants of the pseudo-first and pseudo-second-order models express that the adsorption process occurs more rapidly over the MCC.

Table 5. $q_{\max }$ of tartrazine and Congo Red according to the Langmuir model using various adsorbents.

\begin{tabular}{|c|c|c|c|}
\hline Contaminant & Adsorbent & $q_{\max }(\mathrm{mg} / \mathrm{g})$ & Reference \\
\hline \multirow{14}{*}{ Tartrazine } & Organobentonite & 40.79 & [23] \\
\hline & $\begin{array}{l}\text { Activated carbon from corn cob modified } \\
\text { with } \mathrm{H}_{2} \mathrm{PO}_{4}\end{array}$ & 89.75 & [69] \\
\hline & Coconut shell & 4.452 & \multirow{2}{*}{ [70] } \\
\hline & Commercial activated carbon & 24.22 & \\
\hline & Chitosan/polyaniline compound & 617.8 & \multirow{3}{*}{ [59] } \\
\hline & Chitosan & 46.4 & \\
\hline & Polyaniline & 434.5 & \\
\hline & Sawdust & 7.71 & [71] \\
\hline & Chicken feathers & 0.097 & [72] \\
\hline & Activated carbon from moringa seeds & 91.27 & \multirow{3}{*}{ [25] } \\
\hline & Activated carbon from babassu bone & 11.99 & \\
\hline & Activated carbon from babassu coconut & 19.20 & \\
\hline & Coconut cellulose & 5.222 & \multirow{2}{*}{$\begin{array}{l}\text { Present } \\
\text { study }\end{array}$} \\
\hline & CTAC modified coconut mesocarp cellulose & 18.412 & \\
\hline \multirow{13}{*}{ Congo Red } & $\begin{array}{l}\text { Residual coconut fiber modified with } \\
\text { hexane and } \mathrm{HCl}\end{array}$ & 181.82 & [73] \\
\hline & $\begin{array}{l}\text { Mucuna pruriens activated carbon modified } \\
\text { with orthophosphoric acid }\end{array}$ & 55.56 & {$[21]$} \\
\hline & $\begin{array}{l}\text { Activated carbon from Cornulaca modified } \\
\text { with } \mathrm{NaOH} \text { and } \mathrm{NaClO}\end{array}$ & 78.19 & \multirow[t]{2}{*}{ [74] } \\
\hline & Cornulaca monacantha & 43.42 & \\
\hline & Pine bark & 3.92 & [75] \\
\hline & Sugar cane bagasse & 4.43 & [76] \\
\hline & Banana peel & 1.721 & [61] \\
\hline & Activated carbon from pine cones & 434.78 & {$[60]$} \\
\hline & Activated carbon from bael shell & 65.039 & [77] \\
\hline & $\begin{array}{l}\text { Zeolitic particles with high silica content } \\
\text { functionalized with } \mathrm{ZnO}\end{array}$ & 161.3 & [22] \\
\hline & $\begin{array}{l}\text { Eggshell membrane chemically modified } \\
\text { with } \mathrm{HCl}\end{array}$ & 117.65 & [68] \\
\hline & Coconut cellulose & 5.222 & \multirow{2}{*}{$\begin{array}{l}\text { Present } \\
\text { study }\end{array}$} \\
\hline & $\begin{array}{l}\text { Coconut mesocarp cellulose modified } \\
\text { with CTAC }\end{array}$ & 18.412 & \\
\hline
\end{tabular}



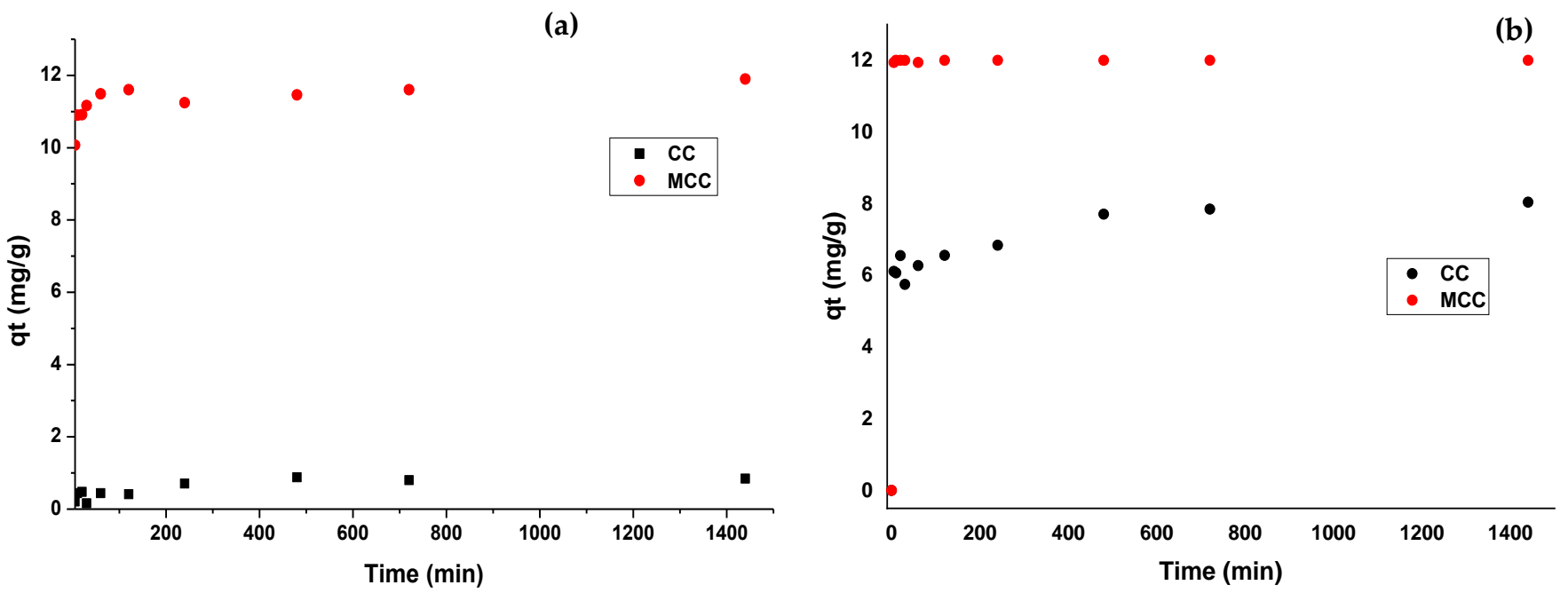

Figure 6. Adsorption kinetics of (a) tartrazine and (b) Congo Red on adsorbents from coconut mesocarp; at $\mathrm{pH} 4,30{ }^{\circ} \mathrm{C}$, initial concentration of $100 \mathrm{mg} / \mathrm{L}$ and $5 \mathrm{mg} / \mathrm{L}$ of adsorbent dose.

Table 6. Adsorption kinetics parameters.

\begin{tabular}{|c|c|c|c|c|c|}
\hline \multirow{2}{*}{ Kinetic Model } & \multirow{2}{*}{ Parameters } & \multicolumn{2}{|c|}{ Tartrazine } & \multicolumn{2}{|c|}{ Congo Red } \\
\hline & & $\mathrm{CC}$ & MCC & $\mathrm{CC}$ & MCC \\
\hline \multirow{4}{*}{ Pseudo-first-order } & $q_{e 1}$ & 4.131 & 11.390 & 7.884 & 11.793 \\
\hline & $k_{1}$ & 0.014 & 0.419 & 0.393 & 0.904 \\
\hline & SS & 0.297 & 0.151 & 5.3278 & 0.005 \\
\hline & $R^{2}$ & 0.454 & 0.640 & 0.995 & 0.999 \\
\hline \multirow{4}{*}{ Pseudo-second-order } & $k_{2}$ & 0.818 & 11.561 & 7.122 & 8.396 \\
\hline & $q_{e 2}$ & 0.033 & 0.116 & 6.775 & 11.787 \\
\hline & SS & 0.227 & 0.088 & 5.971 & 0.005 \\
\hline & $R^{2}$ & 0.533 & 0.999 & 0.997 & 0.999 \\
\hline \multirow{4}{*}{ Elovich } & $\beta$ & 0.131 & 1.860 & 3.497 & 11.743 \\
\hline & $\alpha$ & 8.560 & 19.642 & 2.626 & 12.828 \\
\hline & SS & 0.082 & 0.122 & 0.603 & 0.036 \\
\hline & $R^{2}$ & 0.756 & 0.987 & 0.985 & 0.998 \\
\hline \multirow{3}{*}{ Intraparticle diffusion } & $k_{3}$ & 0.066 & 2.048 & 1.138 & 9.3 \\
\hline & SS & 0.134 & 0.163 & 27.665 & 0.007 \\
\hline & $R^{2}$ & 0.456 & 0.867 & 0.632 & 0.999 \\
\hline
\end{tabular}

The obtained values of $\alpha$ obtained are higher when using MCC than CC, showing that the adsorption rate of the contaminant on CC is slower with respect to MCC. This could be explained by the higher number of protonated sorption active sites on the surface of CTACmodified cellulose. Cellulose has a large presence of adsorption sites, mostly negatively charged (Figure 2a and Table 3), while MCC has $\mathrm{C}_{6} \mathrm{H}_{6}-\mathrm{Cl}$ on its surface (Figure $2 \mathrm{~b}$ ) that deforms after the capture of the group $-\mathrm{SO}_{3}$ of the anionic dyes $\mathrm{CR}$ and tartrazine. Similar results were presented in the removal of dyes on adsorbents modified with surfactants, especially CTAB, such as celery [82] and expanded graphite [83].

Although bioadsorbents of plant origin have multiple options for titration, their use as adsorbents for pollutants present in aqueous solution is of great importance due to their availability in countries characterized by their nature and agricultural productivity, high efficiency removal, because they are an alternative solution to the problem generated 
by poor waste disposal and its low energy consumption. Thus, one of the purposes of using these materials is their reuse as a biodegradable material for the treatment of contaminated wastewater to extend its useful life and generate less amount of contaminated waste. In this sense, the reuse of bioadsorbents has been studied after their regeneration through desorption cycles with $\mathrm{NaOH}, \mathrm{HCl}$, acetic acid and mixtures of organic solvents [26], reporting removal efficiencies $>60 \%$ after six cycles of adsorption-desorption [27]. It is highlighted that the life cycle of these biomasses closes with the immobilization or stabilization of the remaining pollutants in them, by means of encapsulation techniques and inactivation by thermal treatment. To address the problem of the disposal of aged adsorbents, immobilization techniques are proposed to reduce the possible migration of pollutants in the event of a possible change in the physical and chemical properties of the waste [84]. One of the immobilization methods is solidification/stabilization in cement matrices as well as inactivation by heat treatment [85].

\section{Conclusions}

The present study presents favorable results regarding tartrazine and Congo Red's adsorption performance on bioadsorbents prepared from coconut mesocarp. From there, it can be concluded that: (1) Coconut mesocarp waste is a good source for cellulose extraction and the modification with cetyl trimethyl ammonium chloride (CTAC), to protonate the surface of the material was efficient for use in the removal of the anionic dyes understudy in a batch system. (2) The extracted cellulose was of good quality, composed mostly of cellulose with traces of lignin and hemicellulose, and $8 \%$ moisture. (3) The FTIR showed the effectiveness of the modification in the structure of the material with symmetric deformation of the $\mathrm{C}_{6} \mathrm{H}_{6}-\mathrm{Cl}$ group in $1472 \mathrm{~cm}^{-1}$ present in the CTAC. (4) The effect of adsorbent dose and initial concentration on the adsorption capacity was evaluated, finding that coconut mesocarp requires modification for efficient removal of anionic dyes. Decreasing the adsorbent dose and increasing the initial concentration favored the removal of contaminants, achieving tartrazine removals of $5.67 \mathrm{mg} / \mathrm{g}$ on CC and $19.61 \mathrm{mg} / \mathrm{g}$ on MCC, and for CR of $15.52 \mathrm{mg} / \mathrm{g}$ on CC and 19.99 with MCC with removal percentages over $97 \%$ with quaternized biomass in all cases. (5) The adsorption isotherms showed the equilibrium of tartrazine on CC and MCC, and it can be said that the model that best fit the process was the Freundlich model. In contrast, $C R^{\prime}$ s removal showed a better fit to the Langmuir model when using CC and to Dubinin-Radushkevich when using MCC. (6) Adsorption kinetics showed that equilibrium was reached at $30 \mathrm{~min}$ and that initially, the removal of the dyes occurred rapidly with about $97 \%$ of the contaminant being removed in the first $5 \mathrm{~min}$.

Author Contributions: C.T.-T., Á.D.G.-D. and Á.V.-O. conceived and designed the paper and wrote the Introduction and Materials and Methods. C.T.-T., Á.D.G.-D. and Á.V.-O. wrote the Results and prepared the figures and tables. Discussions and Conclusions were the collective work of all authors. The writing-review and editing was performed by Á.D.G.-D. All authors have read and agreed to the published version of the manuscript.

Funding: This research received no external funding.

Institutional Review Board Statement: Not applicable.

Informed Consent Statement: Not applicable.

Data Availability Statement: The data that support the findings of this study are available in the open literature.

Acknowledgments: The authors express their gratitude to Universidad de Cartagena for providing equipment and reagents to conduct this research.

Conflicts of Interest: The authors declare no conflict of interest. 


\section{References}

1. Gautam, R.K.; Gautam, P.K.; Banerjee, S.; Rawat, V.; Soni, S.; Sharma, S.K.; Chattopadhyaya, M.C. Removal of tartrazine by activated carbon biosorbents of Lantana camara: Kinetics, equilibrium modeling and spectroscopic analysis. J. Environ. Chem. Eng. 2015, 3, 79-88. [CrossRef]

2. Adegoke, K.A.; Bello, O.S. Dye sequestration using agricultural wastes as adsorbents. Water Resour. Ind. 2015, 12, 8-24. [CrossRef]

3. Shalla, A.H.; Bhat, M.A.; Yaseen, Z. Hydrogels for removal of recalcitrant organic dyes: A conceptual overview. J. Environ. Chem. Eng. 2018, 6, 5938-5949. [CrossRef]

4. Mani, S.; Bharagava, R.N.; Chowdhary, P. Textile Wastewater Dyes: Toxicity Profile and Treatment Approaches. In Emerging and Eco-Friendly Approaches for Waste Management; Springer: Singapore, 2018; Volume 1, pp. 219-244. ISBN 9789811086694.

5. Hussain, I.; Li, Y.; Qi, J.; Li, J.; Wang, L. Nitrogen-enriched carbon sheet for Methyl blue dye adsorption. J. Environ. Manag. 2018, 215, 123-131. [CrossRef] [PubMed]

6. Angelika, T.; Kamila, M.; Andrzej, P. Synthetic organic dyes as contaminants of the aquatic environment and their implications for ecosystems: A review. Sci. Total Environ. 2020, 717, 137222.

7. Javaid, R.; Qazi, U.Y. Catalytic oxidation process for the degradation of synthetic dyes: An overview. Int. J. Environ. Res. Public Health 2019, 16, 2066. [CrossRef] [PubMed]

8. Food, E.; Authority, S.; Baert, K.; Levorato, S.; Binaglia, M. Dyes in aquaculture and reference points for action. EFSA J. 2017, 15,4920 .

9. Lellis, B.; Fávaro-Polonio, C.Z.; Pamphile, J.A.; Polonio, J.C. Effects of textile dyes on health and the environment and bioremediation potential of living organisms. Biotechnol. Res. Innov. 2019, 3, 275-290. [CrossRef]

10. Kaykhaii, M.; Sasani, M.; Marghzari, S. Removal of Dyes from the Environment by Adsorption Process. Chem. Mater. Eng. 2018, 6, 31-35. [CrossRef]

11. Kooh, M.R.R.; Lim, L.B.L.; Lim, L.H.; Malik, O.A. Phytoextraction potential of water fern (Azolla pinnata) in the removal of a hazardous dye, methyl violet 2B: Artificial neural network modelling. Int. J. Phytoremediat. 2018, 20, 424-431. [CrossRef]

12. Rodrigues de Almeida, E.J.; Christofoletti Mazzeo, D.E.; Deroldo Sommaggio, L.R.; Marin-Morales, M.A.; Rodrigues de Andrade, A.; Corso, C.R. Azo dyes degradation and mutagenicity evaluation with a combination of microbiological and oxidative discoloration treatments. Ecotoxicol. Environ. Saf. 2019, 183, 109484. [CrossRef]

13. Olusegun, O.A.; Martincigh, B.S. Allergic contact dermatitis: A significant environmental and occupational skin disease. Int. J. Dermatol. 2021, in press. [CrossRef] [PubMed]

14. Moreno-Sader, K.; García-Padilla, A.; Realpe, A.; Acevedo-Morantes, M.; Soares, J. Removal of Heavy Metal Water Pollutants (Co2 ${ }^{+}$ and $\mathrm{Ni}^{+}$) Using Polyacrylamide/Sodium Montmorillonite (PAM/Na-MMT) Nanocomposites. ACS Omega 2019, 4, 10834-10844. [CrossRef]

15. Zhang, Y.; Song, X.; Xu, Y.; Shen, H.; Kong, X.; Xu, H. Utilization of wheat bran for producing activated carbon with high specific surface area via $\mathrm{NaOH}$ activation using industrial furnace. J. Clean. Prod. 2019, 210, 366-375. [CrossRef]

16. Tan, C.H.C.; Sabar, S.; Hussin, M.H. Development of immobilized microcrystalline cellulose as an effective adsorbent for methylene blue dye removal. South Afr. J. Chem. Eng. 2018, 26, 11-24. [CrossRef]

17. Khurana, I.; Saxena, A.; Khurana, J.M.; Rai, P.K. Removal of Dyes Using Graphene-Based Composites: A Review. Water Air Soil Pollut. 2017, 228, 180. [CrossRef]

18. Kono, H.; Ogasawara, K.; Kusumoto, R.; Oshima, K.; Hashimoto, H.; Shimizu, Y. Cationic cellulose hydrogels cross-linked by poly(ethylene glycol): Preparation, molecular dynamics, and adsorption of anionic dyes. Carbohydr. Polym. 2016, 152, 170-180. [CrossRef]

19. Jiang, Z.; Hu, D. Molecular mechanism of anionic dyes adsorption on cationized rice husk cellulose from agricultural wastes. J. Mol. Liq. 2019, 276, 105-114. [CrossRef]

20. Safari, M.; Khataee, A.; Darvishi Cheshmeh Soltani, R.; Rezaee, R. Ultrasonically facilitated adsorption of an azo dye onto nanostructures obtained from cellulosic wastes of broom and cooler straw. J. Colloid Interface Sci. 2018, 522, 228-241. [CrossRef]

21. Igwegbe, C.A.; Onyechi, P.C.; Onukwuli, O.D.; Nwokedi, I.C. Adsorptive Treatment of Textile Wastewater Using Activated Carbon Produced from Mucuna pruriens Seed Shells. World J. Eng. Technol. 2016, 4, 21-37. [CrossRef]

22. Madan, S.; Shaw, R.; Tiwari, S.; Tiwari, S.K. Adsorption dynamics of Congo red dye removal using ZnO functionalized high silica zeolitic particles. Appl. Surf. Sci. 2019, 487, 907-917. [CrossRef]

23. Otavo-Loaiza, R.A.; Sanabria-González, N.R.; Giraldo-Gómez, G.I. Tartrazine Removal from Aqueous Solution by HDTMA-BrModified Colombian Bentonite. Sci. World J. 2019, 2019, 2042563. [CrossRef] [PubMed]

24. Li, Z.; Hanafy, H.; Zhang, L.; Sellaoui, L.; Schadeck Netto, M.; Oliveira, M.L.S.; Seliem, M.K.; Luiz Dotto, G.; Bonilla-Petriciolet, A.; $\mathrm{Li}, \mathrm{Q}$. Adsorption of congo red and methylene blue dyes on an ashitaba waste and a walnut shell-based activated carbon from aqueous solutions: Experiments, characterization and physical interpretations. Chem. Eng. J. 2020, 388, 124263. [CrossRef]

25. Reck, I.M.; Paixão, R.M.; Bergamasco, R.; Vieira, M.F.; Vieira, A.M.S. Removal of tartrazine from aqueous solutions using adsorbents based on activated carbon and Moringa oleifera seeds. J. Clean. Prod. 2018, 171, 85-97. [CrossRef]

26. Mashkoor, F.; Nasar, A.; Asiri, A.M. Exploring the Reusability of Synthetically Contaminated Wastewater Containing Crystal Violet Dye using Tectona grandis Sawdust as a Very Low-Cost Adsorbent. Sci. Rep. 2018, 8, 8314. [CrossRef] [PubMed]

27. Dogar, S.; Nayab, S.; Farooq, M.Q.; Said, A.; Kamran, R.; Duran, H.; Yameen, B. Utilization of biomass fly ash for improving quality of organic dye-contaminated water. ACS Omega 2020, 5, 15850-15864. [CrossRef] 
28. Magdy, Y.H.; Altaher, H. Kinetic analysis of the adsorption of dyes from high strength wastewater on cement kiln dust. J. Environ. Chem. Eng. 2018, 6, 834-841. [CrossRef]

29. Trujillo, A.F.; Arias, L.S. The coconut, a renewable resource for thedesign of green materials. Entre Cienc. Ing. 2013, 7, 93-100.

30. Andrade, S.N.; Veloso, C.M.; Fontan, R.C.I.; Bonomo, R.C.F.; Santos, L.S.; Brito, M.J.P.; Diniz, G.A. Chemical-activated carbon from coconut (Cocos nucifera) endocarp waste and its application in the adsorption of $B$-lactoglobulin protein. Rev. Mex. Ing. Quimica 2018, 17, 436-475.

31. Inseemeesak, B.; Areeprasert, C. Fiber extraction and energy recovery from Cocos nucifera Linn mesocarp residues employing steam explosion and anaerobic digestion. Ind. Crop. Prod. 2020, 147, 112180. [CrossRef]

32. Collazo-Bigliardi, S.; Ortega-Toro, R.; Chiralt Boix, A. Isolation and characterisation of microcrystalline cellulose and cellulose nanocrystals from coffee husk and comparative study with rice husk. Carbohydr. Polym. 2018, 191, 205-215. [CrossRef] [PubMed]

33. Xu, J.; Krietemeyer, E.F.; Boddu, V.M.; Liu, S.X.; Liu, W.C. Production and characterization of cellulose nanofibril (CNF) from agricultural waste corn stover. Carbohydr. Polym. 2018, 192, 202-207. [CrossRef]

34. Herrera-Barros, A.; Tejada-Tovar, C.; Villabona-Ortíz, A.; Gonzalez-Delgado, A.D.; Benitez-Monroy, J. Cd (II) and Ni (II) uptake by novel biosorbent prepared from oil palm residual biomass and $\mathrm{Al}_{2} \mathrm{O}_{3}$ nanoparticles. Sustain. Chem. Pharm. 2020, 15, 100216. [CrossRef]

35. Al-Ghouti, M.A.; Da'ana, D.A. Guidelines for the use and interpretation of adsorption isotherm models: A review. J. Hazard. Mater. 2020, 393, 122383. [CrossRef]

36. Afroze, S.; Sen, T.K. A review on heavy metal ions and dye adsorption from water by agricultural solid waste adsorbents. Water Air Soil Pollut. 2018, 229, 225. [CrossRef]

37. Wang, J.; Guo, X. Adsorption kinetic models: Physical meanings, applications, and solving methods. J. Hazard. Mater. 2020, 390, 122156. [CrossRef] [PubMed]

38. Herlina Sari, N.; Wardana, I.N.G.; Irawan, Y.S.; Siswanto, E. Characterization of the Chemical, Physical, and Mechanical Properties of $\mathrm{NaOH}$-treated Natural Cellulosic Fibers from Corn Husks. J. Nat. Fibers 2018, 15, 545-558. [CrossRef]

39. Fan, C.; Zhang, Y. Adsorption isotherms, kinetics and thermodynamics of nitrate and phosphate in binary systems on a novel adsorbent derived from corn stalks. J. Geochem. Explor. 2018, 188, 95-100. [CrossRef]

40. Bryś, A.; Bryś, J.; Ostrowska-Ligęza, E.; Kaleta, A.; Górnicki, K.; Głowacki, S.; Koczoń, P. Wood biomass characterization by DSC or FT-IR spectroscopy. J. Therm. Anal. Calorim. 2016, 126, 27-35. [CrossRef]

41. Zhang, Q.; Zhang, P.; Pei, Z.; Wang, D. Investigation on characteristics of corn stover and sorghum stalk processed by ultrasonic vibration-assisted pelleting. Renew. Energy 2017, 101, 1075-1086. [CrossRef]

42. Nagarajan, K.J.; Balaji, A.N.; Ramanujam, N.R. Extraction of cellulose nanofibers from cocos nucifera var aurantiaca peduncle by ball milling combined with chemical treatment. Carbohydr. Polym. 2012, 212, 312-322. [CrossRef] [PubMed]

43. Ilyas, R.A.; Sapuan, S.M.; Ishak, M.R. Isolation and characterization of nanocrystalline cellulose from sugar palm fibres (Arenga Pinnata). Carbohydr. Polym. 2018, 181, 1038-1051. [CrossRef] [PubMed]

44. Su, J.; He, S.; Zhao, Z.; Liu, X. Efficient preparation of cetyltrimethylammonium bromide-graphene oxide composite and its adsorption of Congo red from aqueous solutions. Colloids Surf. A 2018, 554, 227-236. [CrossRef]

45. Uma Maheswari, C.; Obi Reddy, K.; Muzenda, E.; Guduri, B.R.; Varada Rajulu, A. Extraction and characterization of cellulose microfibrils from agricultural residue-Cocos nucifera L. Biomass Bioenergy 2012, 46, 555-563. [CrossRef]

46. Ouassif, H.; Moujahid, E.M.; Lahkale, R.; Sadik, R.; Bouragba, F.Z.; Sabbar, E.M.; Diouri, M. Zinc-Aluminum layered double hydroxide: High efficient removal by adsorption of tartrazine dye from aqueous solution. Surf. Interfaces 2020, $18,100401$. [CrossRef]

47. Singh, S.; Perween, S.; Ranjan, A. Dramatic enhancement in adsorption of congo red dye in polymer-nanoparticle composite of polyaniline-zinc titanate. J. Environ. Chem. Eng. 2021, 9, 105149. [CrossRef]

48. Kumar, R.; Ansari, M.O.; Parveen, N.; Barakat, M.A.; Cho, M.H. Simple route for the generation of differently functionalized PVC@graphene-polyaniline fiber bundles for the removal of Congo red from wastewater. RSC Adv. 2015, 5, 61486-61494. [CrossRef]

49. Aiyesanmi, A.F.; Adebayo, M.A.; Arowojobe, Y. Biosorption of Lead and Cadmium from Aqueous Solution in Single and Binary Systems Using Avocado Pear Exocarp: Effects of Competing Ions. Anal. Lett. 2020, 53, 2868-2885. [CrossRef]

50. Kumar, A.; Negi, Y.S.; Choudhary, V.; Bhardwaj, N.K. Characterization of Cellulose Nanocrystals Produced by Acid-Hydrolysis from Sugarcane Bagasse as Agro-Waste. J. Mater. Phys. Chem. 2014, 2, 1-8. [CrossRef]

51. Mohamed Pauzan, A.S.; Ahad, N. Biomass Modification Using Cationic Surfactant Cetyltrimethylammonium Bromide (CTAB) to Remove Palm-Based Cooking Oil. J. Chem. 2018, 2018, 5059791.

52. Bakar, A.H.B.A.; Koay, Y.S.; Ching, Y.C.; Abdullah, L.C.; Choong, T.S.Y.; Alkhatib, M.; Mobarekeh, M.N.; Zahri, N.A.M. Removal of fluoride using quaternized palm kernel shell as adsorbents: Equilibrium isotherms and kinetics studies. BioResources 2016, $11,4485-4511$.

53. Wang, H.; Wang, S.; Gao, Y. Cetyl trimethyl ammonium bromide modified magnetic biochar from pine nut shells for efficient removal of acid chrome blue K. Bioresour. Technol. 2020, 312, 123564. [CrossRef]

54. Hu, Q.; Chen, N.; Feng, C.; Hu, W.; Liu, H. Kinetic and isotherm studies of nitrate adsorption on granular Fe-Zr-chitosan complex and electrochemical reduction of nitrate from the spent regenerant solution. RSC Adv. 2016, 6, 61944-61954. [CrossRef] 
55. Bhattacharya, A.K.; Venkobachar, C. Removal of Cadmium (II) by Low Cost Adsorbents. J. Environ. Eng. 1984, 110, 110-122. [CrossRef]

56. Santana, S.A.A.; Vieira, A.P.; da Silva Filho, E.C.; Melo, J.C.P.; Airoldi, C. Immobilization of ethylenesulfide on babassu coconut epicarp and mesocarp for divalent cation sorption. J. Hazard. Mater. 2010, 174, 714-719. [CrossRef]

57. Vieira, A.P.; Santana, S.A.A.; Bezerra, C.W.B.; Silva, H.A.S.; Chaves, J.A.P.; de Melo, J.C.P.; da Silva Filho, E.C.; Airoldi, C. Kinetics and thermodynamics of textile dye adsorption from aqueous solutions using babassu coconut mesocarp. J. Hazard. Mater. 2009, 166, 1272-1278. [CrossRef]

58. Vieira, A.P.; Santana, S.A.A.; Bezerra, C.W.B.; Silva, H.A.S.; Chaves, J.A.P.; Melo, J.C.P.; Filho, E.C.S.; Airoldi, C. Removal of textile dyes from aqueous solution by babassu coconut epicarp (Orbignya speciosa). Chem. Eng. J. 2011, 173, 334-340. [CrossRef]

59. Sahnoun, S.; Boutahala, M. Adsorption removal of tartrazine by chitosan/polyaniline composite: Kinetics and equilibrium studies. Int. J. Biol. Macromol. 2018, 114, 1345-1353. [CrossRef] [PubMed]

60. Dawood, S.; Sen, T.K.; Phan, C. Synthesis and characterisation of novel-activated carbon from waste biomass pine cone and its application in the removal of congo red dye from aqueous solution by adsorption. Water Air Soil Pollut. 2014, 225, 1818. [CrossRef]

61. Mondal, N.K.; Kar, S. Potentiality of banana peel for removal of Congo red dye from aqueous solution: Isotherm, kinetics and thermodynamics studies. Appl. Water Sci. 2018, 8, 157. [CrossRef]

62. Kırbıyık, Ç.; Pütün, A.E.; Pütün, E. Equilibrium, kinetic, and thermodynamic studies of the adsorption of Fe(III) metal ions and 2,4-dichlorophenoxyacetic acid onto biomass-based activated carbon by $\mathrm{ZnCl}_{2}$ activation. Surf. Interfaces 2017, 8, 182-192. [CrossRef]

63. Chukwuemeka-Okorie, H.O.; Ekuma, F.K.; Akpomie, K.G.; Nnaji, J.C.; Okereafor, A.G. Adsorption of tartrazine and sunset yellow anionic dyes onto activated carbon derived from cassava sievate biomass. Appl. Water Sci. 2021, 11, 27. [CrossRef]

64. Ezekoye, O.M.; Akpomie, K.G.; Eze, S.I.; Chukwujindu, C.N.; Ani, J.U.; Ujam, O.T. Biosorptive interaction of alkaline modified Dialium guineense seed powders with ciprofloxacin in contaminated solution: Central composite, kinetics, isotherm, thermodynamics, and desorption. Int. J. Phytoremediat. 2020, 22, 1028-1037. [CrossRef]

65. Kumari, S.; Mankotia, D.; Chauhan, G.S. Crosslinked cellulose dialdehyde for Congo red removal from its aqueous solutions. J. Environ. Chem. Eng. 2016, 4, 1126-1136. [CrossRef]

66. Shen, Z.; Zhang, Y.; McMillan, O.; Jin, F.; Al-Tabbaa, A. Characteristics and mechanisms of nickel adsorption on biochars produced from wheat straw pellets and rice husk. Environ. Sci. Pollut. Res. 2017, 24, 12809-12819. [CrossRef] [PubMed]

67. Elmoubarki, R.; Mahjoubi, F.Z.; Tounsadi, H.; Moustadraf, J.; Abdennouri, M.; Zouhri, A.; El Albani, A.; Barka, N. Adsorption of textile dyes on raw and decanted Moroccan clays: Kinetics, equilibrium and thermodynamics. Water Resour. Ind. 2015, 9, 16-29. [CrossRef]

68. Parvin, S.; Biswas, B.K.; Rahman, M.A.; Rahman, M.H.; Anik, M.S.; Uddin, M.R. Study on adsorption of Congo red onto chemically modified egg shell membrane. Chemosphere 2019, 236, 124326. [CrossRef] [PubMed]

69. Zhang, J.; Zhang, P.; Zhang, S.; Zhou, Q. Comparative Study on the Adsorption of Tartrazine and Indigo Carmine onto Maize Cob Carbon. Sep. Sci. Technol. 2014, 49, 877-886. [CrossRef]

70. Gupta, V.K.; Jain, R.; Shrivastava, M.; Nayak, A. Equilibrium and Thermodynamic Studies on the Adsorption of the Dye Tartrazine onto Waste "Coconut Husks" Carbon and Activated Carbon. J. Chem. Eng. Data 2010, 55, 5083-5090. [CrossRef]

71. Banerjee, S.; Chattopadhyaya, M.C. Adsorption characteristics for the removal of a toxic dye, tartrazine from aqueous solutions by a low cost agricultural by-product. Arab. J. Chem. 2017, 10, S1629-S1638. [CrossRef]

72. Mittal, A.; Kurup, L.; Mittal, J. Freundlich and Langmuir adsorption isotherms and kinetics for the removal of Tartrazine from aqueous solutions using hen feathers. J. Hazard. Mater. 2007, 146, 243-248. [CrossRef]

73. Rani, K.C.; Naik, A.; Chaurasiya, R.S.; Raghavarao, K.S.M.S. Removal of toxic Congo red dye from water employing low-cost coconut residual fiber. Water Sci. Technol. 2017, 75, 2225-2236. [CrossRef]

74. Manirethan, V.; Gupta, N.; Balakrishnan, R.M.; Raval, K. Batch and continuous studies on the removal of heavy metals from aqueous solution using biosynthesised melanin-coated PVDF membranes. Environ. Sci. Pollut. Res. 2019, 27, 24723-24737. [CrossRef]

75. Litefti, K.; Freire, M.S.; Stitou, M.; González-Álvarez, J. Adsorption of an anionic dye (Congo red) from aqueous solutions by pine bark. Sci. Rep. 2019, 9, 16530. [CrossRef]

76. Raymundo, A.S.; Zanarotto, R.; Belisário, M.; de Pereira, M.G.; Ribeiro, J.N.; Nardy Ribeiro, A.V.F. Evaluation of sugar-cane bagasse as bioadsorbent in the textile wastewater treatment contaminated with Carcinogenic congo red dye. Braz. Arch. Biol. Technol. 2010, 53, 931-938. [CrossRef]

77. Ahmad, R.; Kumar, R. Adsorptive removal of congo red dye from aqueous solution using bael shell carbon. Appl. Surf. Sci. 2010, 257, 1628-1633. [CrossRef]

78. Kim, U.J.; Kimura, S.; Wada, M. Highly enhanced adsorption of Congo red onto dialdehyde cellulose-crosslinked cellulosechitosan foam. Carbohydr. Polym. 2019, 214, 294-302. [CrossRef] [PubMed]

79. Sharma, A.; Siddiqui, Z.M.; Dhar, S.; Mehta, P.; Pathania, D. Adsorptive removal of congo red dye (CR) from aqueous solution by Cornulaca monacantha stem and biomass-based activated carbon: Isotherm, kinetics and thermodynamics. Sep. Sci. Technol. 2019, 54, 916-929. [CrossRef] 
80. Marques, B.S.; Frantz, T.S.; Sant'Anna Cadaval Junior, T.R.; de Almeida Pinto, L.A.; Dotto, G.L. Adsorption of a textile dye onto piaçava fibers: Kinetic, equilibrium, thermodynamics, and application in simulated effluents. Environ. Sci. Pollut. Res. 2019, 26, 28584-28592. [CrossRef]

81. Tran, H.N.; You, S.J.; Hosseini-Bandegharaei, A.; Chao, H.P. Mistakes and inconsistencies regarding adsorption of contaminants from aqueous solutions: A critical review. Water Res. 2017, 120, 88-116. [CrossRef] [PubMed]

82. Mohebali, S.; Bastani, D.; Shayesteh, H. Equilibrium, kinetic and thermodynamic studies of a low-cost biosorbent for the removal of Congo red dye: Acid and CTAB-acid modified celery (Apium graveolens). J. Mol. Struct. 2019, 1176, 181-193. [CrossRef]

83. Xu, C.; Wang, H.; Yang, W.; Ma, L.; Lin, A. Expanded Graphite Modified by CTAB-KBr/H3PO4 for Highly Efficient Adsorption of Dyes. J. Polym. Environ. 2018, 26, 1206-1217. [CrossRef]

84. Zhang, S.; Zhao, Y.; Guo, Z.; Ding, H. Stabilization/solidification of hexavalent chromium containing tailings using low-carbon binders for cemented paste backfill. J. Environ. Chem. Eng. 2021, 9, 104738.

85. Shamsollahi, Z.; Partovinia, A. Recent advances on pollutants removal by rice husk as a bio-based adsorbent: A critical review. J. Environ. Manag. 2019, 246, 314-323. 